\title{
ESTRATIGRAFÍA Y PETROGRAFÍA DE LAS ROCAS ÍGNEAS EN LA CORDILLERA DE TALAMANCA, COSTA RICA
}

\author{
STRATIGRAPHY AND PETROGRAPHY OF THE IGNEOUS ROCKS IN THE \\ TALAMANCA CORDILLERA, COSTA RICA
}

\author{
Aristides Alfaro ${ }^{1 *}$, Percy Denyer ${ }^{2}$, Guillermo E. Alvarado ${ }^{3}$, Esteban Gazel $^{1}$ y \\ Carlos Chamorro ${ }^{4}$
}
${ }^{1}$ Earth and Atmospheric Sciences, Cornell University, Ithaca, Nueva York. ${ }^{2}$ Centro de Investigaciones en Ciencias Geológicas, Universidad de Costa Rica, San José, Costa Rica.
${ }^{3}$ Instituto Costarricense de Electricidad, San José, Costa Rica. ${ }^{4}$ Escuela Centroamericana de Geología, Universidad de Costa Rica, San José, Costa Rica. Autor para contacto: aja268@cornell.edu/arisalfaro@gmail.com

(Recibido: 04/04/2017; aceptado: 06/06/2017)

\begin{abstract}
In the Talamanca Cordillera, the widespread magmatic products record Neogene and Quaternary intrusive and extrusive phases. Generally, it is possible to recognize three magmatic stages: 1) Volcanic series older than Upper Miocene, ranging from $\sim 17$ to 11 mya; 2) Plutonic events during the Middle-Upper Miocene, between 12,5 and 7,5 mya, known as Talamanca Intrusive Group or Granite-Gabbro Series of Talamanca; c) Post-intrusive magmatic pulses from Neogene-Quaternary, whose temporal range extends from $\sim 5$ to 2 mya. For the first time it is proposed here a differentiation of post-intrusive magmas into three units by petrographic criteria: a) Kamuk Unit, andesites with labradorite-type plagioclase and occasional orthopyroxene. b) Durika Unit, defined by andesine-type plagioclase and the presence of biotite phenocrysts as the predominant ferromagnesian phase. c) Rio Lori Unit, whose products were not sampled in this study, but based in previous work they are characterized by the presence of quartz, amphibole and biotite phenocrysts. Additionally, we provide a new contribution to the geologic cartography of the Talamanca Cordillera, with a geological description of the summits of Cuerici, Ena, Durika, Utyum, Kamuk, fila Pittier and Echandi. We also present new data referring to the geology of the summit of Chirripo.

Keywords: Talamanca, igneous rocks, intrusive, basalt, andesite, latite, dacite.
\end{abstract}




\begin{abstract}
Resumen: En la cordillera de Talamanca los productos del magmatismo se encuentran ampliamente distribuidos, y corresponden con episodios intrusivos y extrusivos del Neógeno y del Cuaternario. En general es posible reconocer tres fases magmáticas: 1) vulcanismo anterior al Mioceno Superior, de unos 17 a 11 millones de años atrás; 2) plutonismo durante el Mioceno Medio-Superior, entre 12,5 y 7,5 millones de años, conocido como Grupo Intrusivo de Talamanca o Granito-Gabro de Talamanca; 3) pulsos magmáticos post-intrusivos del Neógeno al Cuaternario, cuyo rango temporal se extiende entre 5 y 2 millones de años. Por primera vez se propone una diferenciación del magmatismo post-intrusivo en tres unidades, separables por aspectos petrográficos: a) Unidad Kámuk, constituida por andesitas con plagioclasa de tipo labradorita y ocasionalmente con ortopiroxeno; b) Unidad Dúrika, definida por plagioclasa de tipo andesina y biotita como fenocristal ferromagnesiano predominante; c) Unidad Río Lori, cuyos productos no fueron recolectados, pero con base en trabajos previos se caracteriza por la presencia de cuarzo, anfíbol y biotita. Se realiza además una contribución a la cartografía geológica de la cordillera de Talamanca, con una descripción geológica de las cimas de Cuericí, Ena, Dúrika, Utyum, Kámuk, fila Pittier y Echandi. También se presentan nuevos datos sobre la geología del cerro Chirripó.

Palabras clave: Talamanca, rocas ígneas, intrusivo, basalto, andesita, latita, dacita.
\end{abstract}

\section{INTRODUCCIÓN}

La cordillera de Talamanca es un sistema montañoso que se extiende entre la región central de Costa Rica y el oeste de Panamá. Sus cimas son los terrenos de mayor elevación en América Central meridional, con altitudes que sobrepasan los 3000 m s.n.m. Los flancos de la cordillera tienden a ser de difícil acceso; con excepción del Chirripó (3820 m s.n.m.) y Buenavista (3491 m s.n.m.), los cerros que la conforman son visitados principalmente por investigadores y montañistas expertos. Existen algunos senderos que permiten adentrarse hacia las partes altas, aunque por lo general las condiciones topográficas y climáticas dificultan el reconocimiento de la región. Dadas estas circunstancias, grandes extensiones de la Talamanca permanecen con escasa o nula información geológica, aún en los albores del siglo XXI.

En este trabajo se presentan por primera vez datos petrográficos de las rocas ígneas en el flanco Pacífico y cima de los cerros Cuericí, Ena, Dúrika, Utyum, Kámuk, fila Pittier y Echandi, además de nuevos aportes a la petrografía del cerro Chirripó. Las descripciones petrográficas completas están disponibles en el volumen 2 de la tesis Caracterización petrográfica y geoquímica de las rocas ígneas en el sector Pacífico de la cordillera de Talamanca, Costa Rica (Alfaro, 2017), en la Escuela Centroamericana de Geología de la Universidad de Costa Rica. En el presente artículo se hace referencia a los resultados de los análisis, tanto en el texto como en el mapa geológico adjunto, y se enfatiza la nueva división estratigráfica propuesta para la cordillera de Talamanca. El objetivo, por lo tanto, es presentar una correlación entre estratigrafía y petrografía para las rocas ígneas de la región; el mapa geológico adjunto pretende ser la representación de un modelo estratigráfico basado en observaciones petrográficas, geoquímicas y cronoestratigráficas, según los nuevos datos disponibles y la contribución de los trabajos anteriores.

\section{CONTEXTO TECTÓNICO}

La región en estudio se encuentra en una zona de convergencia de placas (Fig. 1), en que la placa del Coco se subduce bajo la placa Caribe y la microplaca de Panamá. Considerando un anteraco fijo, la placa del Coco se aproxima a la península de Osa a $85,1 \pm 4,2 \mathrm{~mm}$ por año en dirección $\mathrm{N} 28^{\circ} \mathrm{E}$, según un modelo tridimensional desarrollado por LaFemina et al. (2009). En este trasfondo, la cordillera de Talamanca se encuentra en una disposición aproximadamente paralela a la fosa Mesoamericana, al igual que el arco volcánico centroamericano que se extiende desde Guatemala hasta la región central de Costa Rica prácticamente sin interrupciones. Sin embargo, es notable la ausencia de volcanes recientes (de $1 \mathrm{mi}$ llón de años o menos) a lo largo de unos $175 \mathrm{~km}$, espacio ocupado por la cordillera de Talamanca 


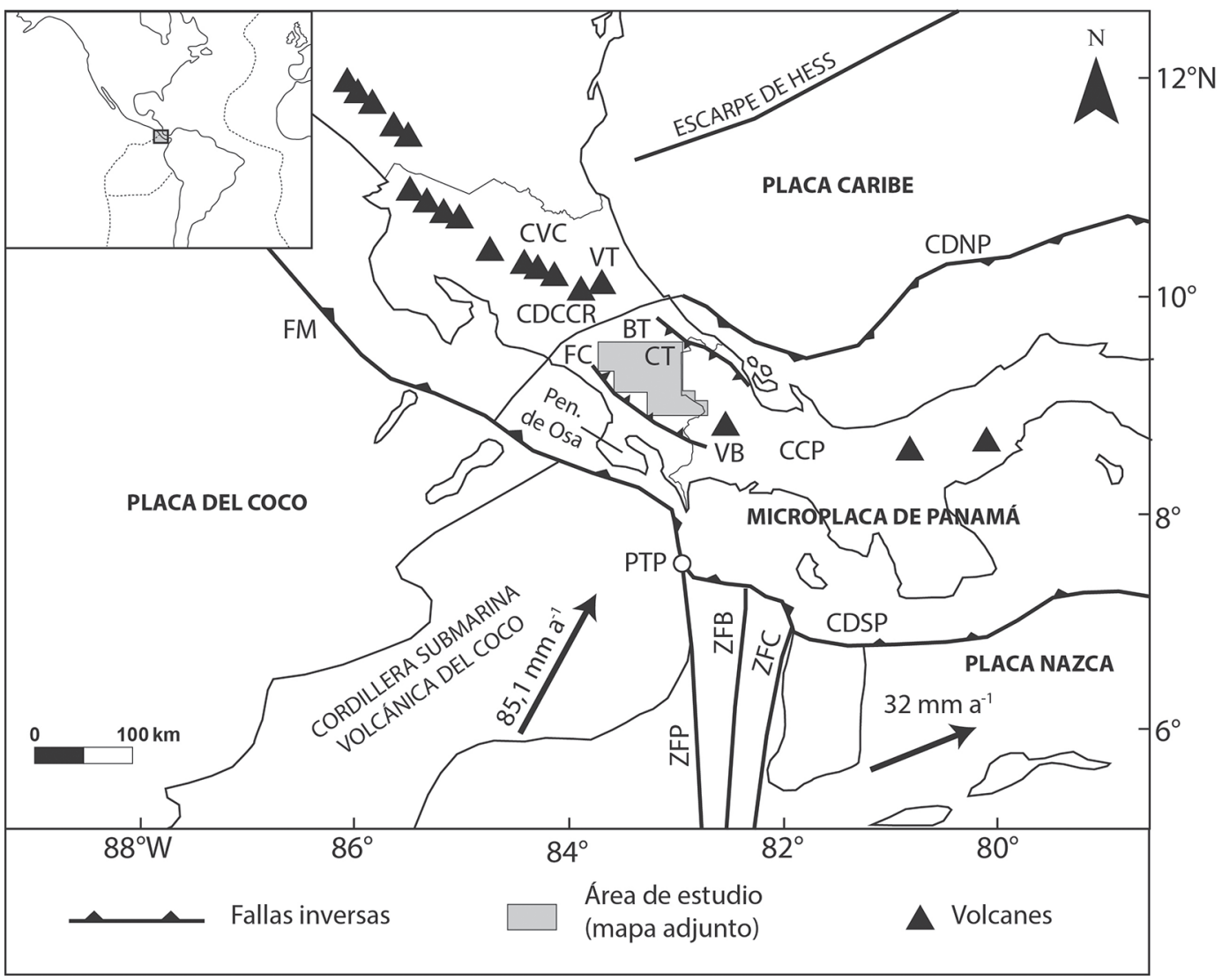

Fig. 1: Contexto tectónico de la región en estudio. La cordillera de Talamanca (CT) se extiende de manera paralela a los cinturones de deformación de Baja Talamanca (BT) y fila Costeña (FC). FM: fosa Mesoamericana; CDCCR: Cinturón Deformado del Centro de Costa Rica; CDNP: Cinturón Deformado del Norte de Panamá; CDSP: Cinturón Deformado del Sur de Panamá; CVC: cordillera Volcánica Central; CCP: cordillera Central de Panamá; VB: volcán Barú; VT: volcán Turrialba; PTP: Punto triple de Panamá; ZFP: Zona de Fractura de Panamá; ZFB: Zona de Fractura de Balboa; ZFC: Zona de Fractura de Coiba; Pen.: península. Los rasgos tectónicos y morfológicos se representan a partir de Montero (2001) y Morell (2015); vectores de velocidad de las placas (flechas rellenas) según LaFemina et al. (2009) y Sella, Dixon y Mao (2002).

y los conjuntos de serranías que la flanquean. Ya Kolarsky, Mann y Montero. (1995) habían demostrado que este espacio sin estratovolcanes entre los volcanes Turrialba en Costa Rica y Barú en Panamá, tiene una anchura similar a la porción más somera de la cordillera del Coco, un rasgo geomorfológico destacable en la placa del Coco.

En la actualidad se considera que el arribo de la cordillera del Coco a la zona de subducción produjo importantes cambios en la configuración tectónica (Montero, 2001) y la evolución geoquímica de la región central y meridional de Costa Rica (Hoernle et al., 2008; Gazel et al., 2009;
Gazel et al., 2011; Gazel et al., 2015), aunque la edad a la que este evento tuvo lugar sigue siendo objeto de debate (ver detalle en MacMillan, Gans y Alvarado, 2004; Alvarado y Gans, 2012; Gazel et al., 2015; Morell, 2015). Una estimación sobre la llegada de la cordillera submarina a la trinchera está más allá de los objetivos que nos ocupan en este trabajo. Empero, el origen de los cinturones de deformación que flanquean la cordillera de Talamanca, fila Costeña en el Pacífico (Fisher, Gardner, Sak, Sánchez, Murphy y Vannuchi, 2004; Sitchler, Fisher, Gardner y Protti, 2007) y Baja Talamanca en el Caribe, serían la respuesta 
a la colisión de la cordillera volcánica submarina. La misma cordillera de Talamanca evidencia deformación en las secuencias volcánicas-sedimentarias del Mioceno Inferior a Medio, que podría ser coetánea con el evento tectónico que transformó el resto de la región.

\section{ANTECEDENTES}

La existencia de rocas ígneas hacia las cimas de la cordillera de Talamanca fue reportada por primera vez por el naturalista William M. Gabb, cuando describió rocas plutónicas en el macizo de Kámuk (Gabb, 1874), e interpretó la cima como un dique proyectándose sobre el cuerpo plutónico (idea que, como veremos más adelante, hoy consideramos esencialmente correcta). En la primera mitad del siglo XX hubo referencias geológicas aisladas sobre la Talamanca, como es el caso de Romanes (1912) con respecto a las estribaciones noroccidentales de la cordillera (cerros de Escazú). Weyl (1957) incluyó por primera vez análisis petrográficos detallados, y una propuesta de diferenciación de las rocas intrusivas en el tramo de la carretera Interamericana entre Villa Mills y San Isidro de El General. Dengo (1962) planteó que hay seis stocks que conforman la serie plutónica de la cordillera de Talamanca, aunque al parecer no visitó las regiones de mayor elevación (sobre los $2500 \mathrm{~m}$ s.n.m.). Entre estos stocks se destacan los nombres "Chirripó", "Dúrika", "Ujum” y "Kámuk", todos ellos correspondientes con cimas. Nuevas incursiones realizadas en la década siguiente (Escalante, 1978; Cities Service Minerals, 1977; Segura, 1978) demostraron que, en efecto, las rocas intrusivas estaban bastante difundidas por los flancos Pacífico y Caribe de la cordillera, lo cual aunado al trabajo pionero de Weyl (1957) parecía concordar bastante bien con la idea de rocas intrusivas en algunos sectores de mayor altitud.

Con el Proyecto de Investigación Minera (Ballmann, 1976; OEA, 1977; ONU, 1975) se logró el primer recorrido transversal del Pacífico al Caribe en la cordillera. Esto hizo posible desarrollar el único perfil geológico completo con información directamente de campo que existe en el área (ONU,
1975; Rivier, 1985). Se obtuvieron datos petrográficos y, por primera vez, datos geoquímicos de las rocas intrusivas y los domos del río Lori.

SAMCOSA (Aluminio Suizo Minería de Costa Rica S. A.), en 1975, pudo haber incluido dentro de su cartografiado las partes superiores de la cordillera; sin embargo, el material actualmente se encuentra perdido, y solo se reconocen algunas características que pudieron haber tenido los mapas de SAMCOSA gracias a la recopilación de Escalante (1978). Lo cierto es que antes de finalizar la década de 1970, las compañías mineras extranjeras al menos tenían la noción de que en las cimas de la Talamanca había otros materiales, predominantemente volcánicos o volcanosedimentarios. Prueba de ello es que el mapa de Escalante (1978) no sobredimensiona las rocas intrusivas en la cima del Kámuk, en la pendiente meridional del Dúrika, ni en el cerro Chirripó. Según nuestras investigaciones, la aproximación cartográfica de Escalante (1978) es la que más acertadamente describió la geología regional de la cordillera en el siglo XX.

La primera datación de la cordillera fue reportada por Berrangé y Whittaker (1977), quienes rebautizaron la serie plutónica como Grupo Comagmático (intrusivo) de Talamanca, nombre utilizado por Sprechmann (1984). Tournon (1984) contribuyó con nuevos datos e interpretaciones sobre el magmatismo de la cordillera, y a su trabajo se debe la descripción más detallada de los domos del río Lori y otros hallazgos de gran relevancia en el sector Caribe: nefelinita en el río Chirripó, basaltos en almohadilla paleógenos en un brazo del río Boyei, y micaesquisto con muscovita, andalusita y cuarzo en fila Bugú. El caso del micaesquisto de la fila Bugú (552300 E, $377400 \mathrm{~N}$, coordenadas M4 del mapa adjunto) sigue siendo aislado y se desconoce si corresponde con metamorfismo de contacto de alta temperatura y baja presión, o si es un bloque de un basamento metamórfico rejuvenecido por las intrusiones (Alvarado y Gans, 2012; Tournon, 1984; Tournon y Alvarado, 1997).

La geología en la cima del cerro Chirripó fue objeto de estudio durante la década de 1980 (Calvo, 1987; Wunsch, 1988). Se desarrolló un cartografiado que demostró la existencia de rocas intrusivas 
y extrusivas en la sección superior del macizo, así como rocas sedimentarias. Por otra parte, Kussmaul (1987) denominó a los intrusivos del área de estudio Grupo Granito-Gabro Talamanca, y estudió sus aspectos petrográficos y cronoestratigráficos, con lo que concluyó que "las rocas básicas son generalmente más antiguas" Kussmaul, 1987, pág. 107).

Appel (1990) aportó una datación K/Ar de una granodiorita en el macizo de Kámuk. Van Uffelen (1993) desarrolló un transecto en las cercanías de la fila Urán, demostrando la predominancia de rocas volcánicas. Tournon y Alvarado (1997) recopilaron la información cartográfica de la región y señalaron la existencia de extensas áreas sin datos geológicos. Abratis (1998) realizó un muestreo de gran parte de la cordillera y aportó valiosos datos geoquímicos que incluyeron elementos mayores, elementos traza e isótopos de $\mathrm{Pb}$ y Nd; Gräfe (1998) proporcionó información sobre la geoquímica de las rocas plutónicas, con el objetivo de estimar la exhumación de la cordillera. En estos dos últimos trabajos la petrografía fue someramente descrita. Las primeras dataciones radiométricas ${ }^{40} \mathrm{Ar} /{ }^{39} \mathrm{Ar}$ de la cordillera de Talamanca fueron las de Gräfe (1998), Abratis y Wörner (2001), y Gräfe, Frisch, Villa y Meschede (2002).

Obando (2004) describió petrográficamente las rocas ígneas del cerro Buenavista. MacMillan et al. (2004) suministraron nuevas dataciones radiométricas ${ }^{40} \mathrm{Ar} /{ }^{39} \mathrm{Ar}$ para las rocas en el macizo de Buenavista, los alrededores de San Isidro y otros sectores aledaños a la cordillera. Denyer y Alvarado (2007) presentaron una nueva versión del mapa geológico de Costa Rica en que proponen que en la cordillera hay granitoides asociados con gabroides del Mioceno MedioSuperior y gabroides más antiguos. Gazel et al. (2009) aportaron nuevas dataciones radiométricas y datos geoquímicos para establecer una correlación entre la contribución del punto caliente de las Galápagos y la evolución geoquímica de Costa Rica y Panamá. Alvarado et al. (2009a) y Alvarado, Barquero, Taylor, López, Cerdas y Murillo (2009b) avanzaron en el cartografiado geológico de las hojas topográficas San Isidro y General, al suroeste de la cordillera. Obando y
Kussmaul (2009) cartografiaron la geología de la hoja Buenos Aires. Ulloa y Delgado (2010) incluyeron importantes análisis petrográficos en los alrededores de Buenos Aires y realizaron varios recorridos hacia la divisoria, donde comprobaron la existencia de rocas plutónicas hacia las cotas de altura inferiores y rocas extrusivas hacia las superiores, además de rocas sedimentarias preintrusivas. Gazel et al. (2011) se refirieron a las adakitas y rocas alcalinas al norte de la cordillera y presentaron nuevos datos geocronológicos y geoquímicos. Alvarado y Gans (2012) recopilaron las dataciones de rocas ígneas y metamórficas de Costa Rica, con lo cual reunieron en su trabajo la información geocronológica disponible en la literatura sobre la Talamanca, y contribuyeron con nuevas dataciones de los intrusivos en los cerros de Escazú. Gazel et al. (2015) destacaron la corteza costarricense en el panorama mundial como el mejor ejemplo conocido de continentalización de una corteza oceánica, e incluyeron muestras de la cordillera de Talamanca para sustentar esa afirmación. Alfaro (2017), cartografió el sector Pacífico de la Talamanca y concluyó la predominancia de las rocas ígneas en las regiones sobre los $2500 \mathrm{~m}$ s.n.m.; aportó además nuevos análisis petrográficos y geoquímicos, los cuales han sido utilizados como base para este trabajo.

\section{MARCO METODOLÓGICO}

Se recolectaron muestras del flanco Pacífico de la cordillera y de las cimas de los cerros Cuericí, Chirripó, Ena, Dúrika, Utyum, Kámuk y Echandi, con el fin de analizarlas petrográficamente. No se consideró el cerro Buenavista debido a que, como se mencionó anteriormente, contaba con análisis petrográficos previos (Obando, 2004); tampoco se incluyeron los cerros Cabécar y Arbolado, que habían sido ya descritos por Ulloa y Delgado (2010). Otras cimas no fueron visitadas debido a dificultades de acceso o por representar elevaciones intermedias entre las citadas al inicio de este párrafo.

De las siete cimas visitadas se logró extraer muestras in situ de rocas ígneas en tres de ellas, Chirripó, Dúrika y Kámuk, donde existen buenos 
afloramientos que merecen estudiarse detenidamente. En la cima del Ena predominan rocas sedimentarias, aunque se encontraron bloques de rocas volcánicas o subvolcánicas. En la cima occidental del Cuericí se halló un dique del que se recolectó una muestra (C031636); las demás corresponden con bloques. En las cimas de los cerros Utyum y Echandi no se encontró ningún afloramiento del macizo rocoso, y por tanto las descripciones se realizan a partir de bloques decimétricos cuspidales, inmersos en los suelos espesos del páramo.

Las secciones delgadas fueron preparadas en el Laboratorio de Petrografía de la Escuela Centroamericana de Geología, Universidad de Costa Rica. El conteo de minerales se realizó con base en seis sectores diferentes de cada sección delgada; en cada uno se obtuvieron los porcentajes mediante comparación con diagramas de porcentajes de minerales, disponibles en la literatura. Los resultados se promediaron para cada mineral. Las secciones fueron analizadas utilizando un microscopio de luz polarizada Nikon. Las fotografías se tomaron con una cámara DS-Fi2, conectada a un dispositivo controlador DS-L3.

El mapa geológico adjunto se realizó utilizando el programa ArcGIS 10.1. La edición final se completó con el programa Adobe Illustrator CS6. Las curvas de nivel corresponden con el proyecto SRTM (Shuttle Radar Topography Mission) de la NASA, de 1 segundo de arco (98 pies, unos 30 metros). La geología estructural del mapa se basa en observaciones de alineamientos, y tomando en cuenta el patrón del Cinturón Deformado del Centro de Costa Rica (Montero, 2001), la fila Costeña (Fisher et al., 2004; Mora, 1979) y la cordillera de Talamanca (Arroyo, 2001; Boschini, 1988; Ulloa y Delgado, 2010). Para las estructuras de la región Caribe se consideraron Compañía Petrolera de Costa Rica (1960); Denyer, Montero y Alvarado (2013); Fisher y Pessagno (1965); ONU (1975).

\section{ESTRATIGRAFÍA Y PETROGRAFÍA}

\section{Aspectos generales sobre el mapa geológico adjunto}

La cordillera de Talamanca está constituida por rocas ígneas, sedimentarias y metamórficas. Como se observa en el mapa adjunto, las unidades estratigráficas ígneas y sedimentarias se extienden ampliamente por ambos flancos de la cordillera. Las rocas metamórficas aquí consideradas (pizarras y esquistos) solo son sectores aislados en el flanco Caribe; la existencia de estas rocas no ha sido confirmada posteriormente. La secuencia volcánica-sedimentaria anterior al Mioceno Medio se encuentra deformada y atravesada por los intrusivos del Mioceno Medio-Superior $(\gamma 2)$. La deformación incluye plegamiento y al menos dos sistemas de fallas: el primero es de fallas de componente inversa con rumbo NW; el segundo es de fallas de desplazamiento de rumbo sinestrales, hacia el NE, que desplazan al primer sistema. La Formación Valle de El General (P-vg) y los aluviones (Q) dispuestos en abanicos hacia el SW son producto del levantamiento y subsecuente erosión de la cordillera de Talamanca.

\section{Estratigrafía ígnea}

La estratigrafía ígnea de la cordillera de Talamanca se divide en tres partes. La primera está constituida por rocas extrusivas anteriores al Mioceno Superior, que en general son más antiguas que el intrusivo principal (por eso también se le llama serie pre-intrusiva). Alfaro (2017) denomina a estas rocas Unidad Lohmann y Formación La Cruz, dependiendo de si se encuentran hacia la parte media o hacia la cima de la serie pre-intrusiva. La segunda parte es el Intrusivo de Talamanca, entre el Mioceno Medio y el Mioceno Superior; el stock de Chirripó es un grupo diferenciable dentro de la serie plutónica observada en la Talamanca. 
La tercera parte la constituyen las rocas ígneas posteriores al intrusivo principal, que aquí se ha dividido en unidades Kámuk, Dúrika y Río Lori. En este apartado se explica cada una de las unidades propuestas. La figura 2 representa la idea estratigráfica del presente trabajo. Los códigos de las unidades en este apartado corresponden con los del mapa adjunto.

\section{Rocas igneas pre-intrusivas:}

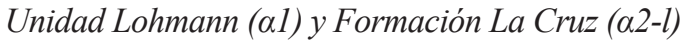

Las rocas ígneas anteriores al intrusivo del Mioceno Medio-Superior (12-7,5 millones de años) se han dividido en Unidad Lohmann y Formación La Cruz. La idea de esta subdivisión es diferenciar las rocas ígneas que se encuentran intercaladas dentro de la secuencia volcano-sedimentaria (Unidad Lohmann) de aquellas que conforman la sección superior de dicha secuencia, que es una serie volcánica efusiva de mayor espesor y que se habría depositado hacia finales del Mioceno Medio, equivalente a la Formación La Cruz definida al sur del Valle Central (Denyer y Arias, 1991). Además, entre ambas unidades habría un espesor considerable de rocas sedimentarias de granulometría fina, que ha sido correlacionada con la Formación Peña Negra en la hoja San Isidro (Alvarado et al., 2009a, siguiendo la definición de Denyer y Arias, 1991). La Unidad Lohmann no se considera diferenciable de la Formación La Cruz a partir de la petrografía, y se ha definido como un grupo aparte con base en criterios geoquímicos, particularmente en que la Formación La Cruz tiene más enriquecimiento de tierras raras que la Unidad Lohmann (Alfaro, 2017). Esta diferenciación tendrá que comprobarse en el futuro con base en nuevas dataciones radiométricas y a partir de más extensa geología de campo.

\section{Descripción}

Se trata de basaltos, andesitas basálticas y andesitas de color gris a negro, que se encuentran asociados con rocas sedimentarias en secuencias estratificadas (Unidad Lohmann) o de forma masiva (Formación La Cruz). Petrográficamente presentan fenocristales de plagioclasa (18-40\%), clinopiroxeno $(0-7 \%)$ y magnetita en menor proporción $(0-4 \%)$, en una matriz intergranular o hialopilítica con prácticamente los mismos componentes (ver cuadro 1 y mapa adjunto). La plagioclasa es labradorita en todos los casos excepto CH031677 (donde es andesina). El olivino es el tercer mineral en abundancia, aunque casi nunca se ve sano y solo se puede inferir su presencia a partir de minerales alterados. Los anfíboles solo aparecen en la matriz de la muestra ECH031693 (sur del cerro Echandi). Los minerales de alteración son frecuentes (calcita, clorita y epidota principalmente).

\section{Estratotipo}

La Unidad Lohmann se definió en el cerro homónimo (517489 E, $373233 \mathrm{~N})$, al sur del macizo de Chirripó; el cerro Lohmann consiste de una serie de brechas de composición volcánica y rocas ígneas efusivas (o sills) buzantes hacia el SW. Esto es observable desde la localidad de San Jerónimo, donde es posible visualizar la pared sureste del cerro Palmital (al SW del Lohmann) constituida por una secuencia de capas de composición volcano-sedimentaria, a juzgar por los bloques hallados en el sendero de ascenso al cerro Lohmann (Fig. 3). La Formación La Cruz tiene algunas exposiciones notables en la arista SW de los cerros Cuericí, aunque el macizo de Buenavista (fuera del área de estudio) se considera aquí el paraestratotipo en la cordillera de Talamanca. 


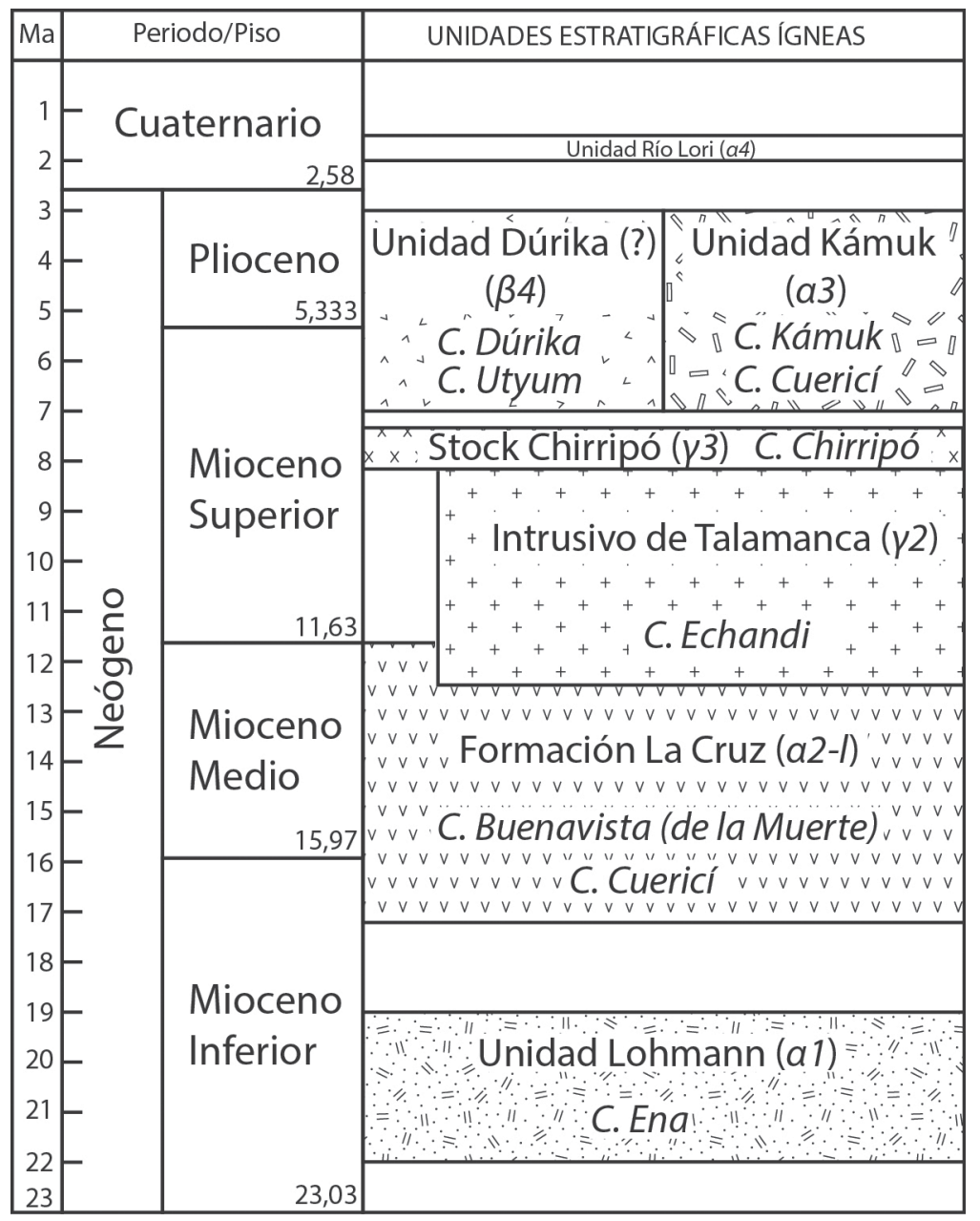

Fig. 2: Columna estratigráfica ígnea de la cordillera de Talamanca. Las edades corresponden con la Tabla Cronoestratigráfica Internacional v2017/02, disponible en www.stratigraphy.org. Ma: millones de años atrás.

\section{Distribución geográfica}

Las rocas pre-intrusivas conforman la mayor parte de la cordillera de Talamanca (Escalante, 1978; presente trabajo). En el mapa geológico adjunto, las rocas pre-intrusivas representan un $54,99 \%$ del área. 3,13\% del área de estudio es de la Unidad Lohmann y 28,78\% de la Formación La Cruz; el resto lo suman otras rocas sedimentarias e ígneas menos conocidas en los flancos de la cordillera. Aún no resulta sencillo separar las unidades estratigráficas ígneas de las sedimentarias, aunque hay sectores donde se observa predominio de las segundas (por ejemplo, secuencia sedimentaria al SW de cerros Utyum) o las primeras (senderos de ascenso a los cerros Kámuk, Dúrika o Cuericí). Es posible que tanto la Unidad Lohmann como la Formación La Cruz aparezcan en todos los macizos de la cordillera de Talamanca, aunque hacia el sureste de la región predominan los materiales asociados con la Formación La Cruz (Alfaro, 2017; también se deduce a partir de Abratis, 1998). En este sector no se observa, además, la secuencia sedimentaria con la cual se encuentra asociada la Unidad Lohmann. 


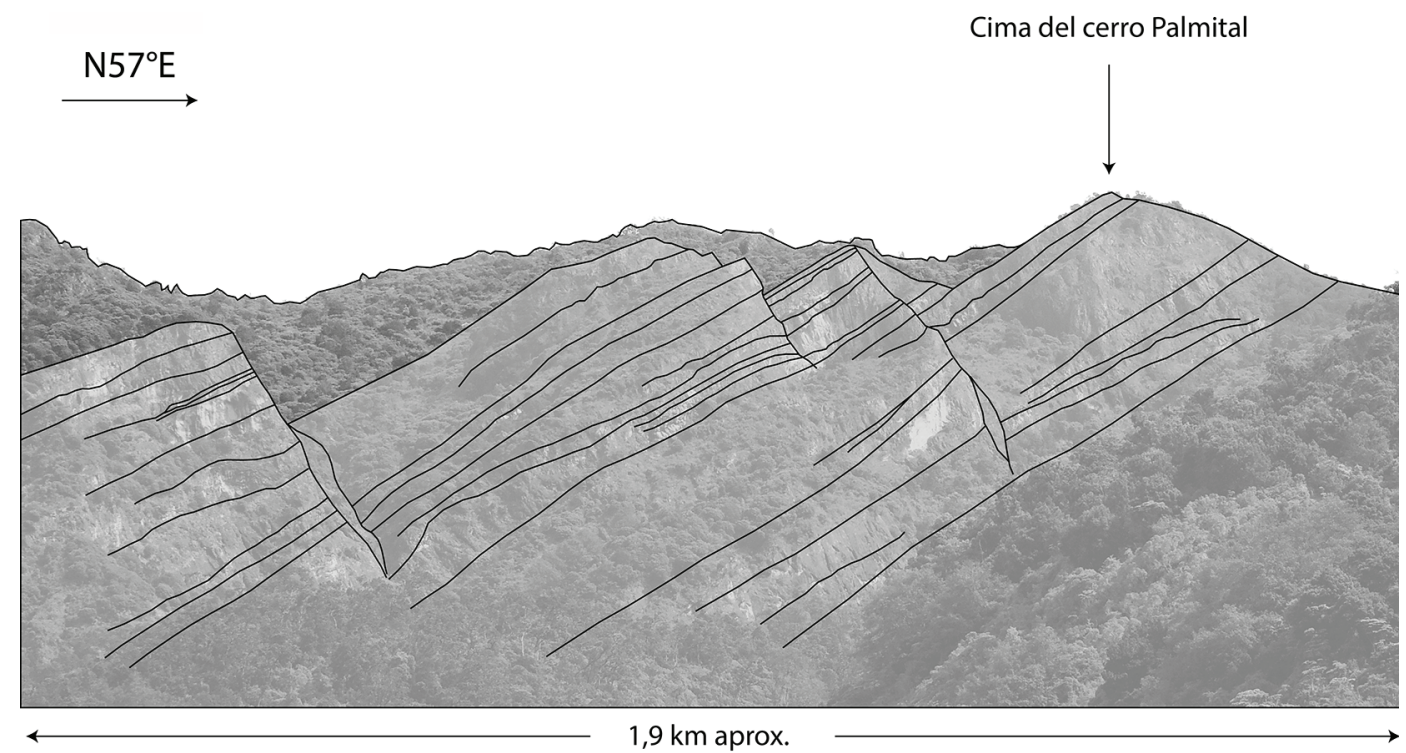

Fig. 3: Secuencia volcánica-sedimentaria anterior al Mioceno Superior (pre-intrusiva), buzando hacia el SW en el cerro Palmital, al sur del macizo de Chirripó.

\section{Edad y correlaciones}

La Formación La Cruz en su localidad tipo, al sur del Valle Central, tiene una edad reportada de 10,90 $\pm 0,10$ millones de años con el método ${ }^{40} \mathrm{Ar} /{ }^{39} \mathrm{Ar}$ (MacMillan et al., 2004). En el cerro Buenavista, al oeste de la cordillera, las dataciones con el mismo método varían entre 14,10 y 10,50 millones de años (MacMillan et al., 2004; Gazel et al., 2009). Cerca de Alturas de Cotón, hacia el sureste, Abratis y Wörner (2001) reportan una andesita basáltica de 16,87 millones de años, considerándose esta como la edad más antigua para la Formación La Cruz en la región (datación n. en las coordenadas U15 del mapa adjunto).

$\mathrm{Si}$ verdaderamente la Formación La Cruz cubre la secuencia volcánica-sedimentaria a partir de los 16-17 millones de años, esto implicaría que la secuencia de la Unidad Lohmann es del Mioceno Inferior o más antigua. Solo una datación con el método K/Ar de un basalto cerca de La Ese, camino a San Isidro, presenta una edad de 21,61 \pm 1,08 millones de años (Jackson, 1991; De
Boer et al., 1995), y coincide con esta suposición. Un sitio que estaría en conflicto con la idea anterior es la datación efectuada por MacMillan et al. (2004) en Finca Mina, Linda Arriba (datación i. en las coordenadas C5, mapa adjunto). Para esta muestra se reporta una edad de 13 millones de años. Debe verificarse si esta muestra corresponde con un cuerpo ígneo intercalado en la secuencia sedimentaria o si se trata de un dique. Si la primera opción es correcta, la edad de la Unidad Lohmann se extendería hasta el Mioceno Medio, y ya no podría diferenciarse de la Formación La Cruz por este criterio. En ese caso, es posible que en ambos casos se trate de remanentes de paleo-estratovolcanes complejos, con variabilidad geoquímica dentro de los mismos aparatos volcánicos, como sucede con los estratovolcanes del Cuaternario (G. Soto, com. escrita, 2018).

El magmatismo representado en la Unidad Lohmann podría asociarse con eventos ígneos coetáneos con el Arco de Sarapiquí (Gazel et al., 2005; Alvarado y Gans, 2012). También podría tener relación temporal con la Formación Pacacua del sur del Valle Central (Denyer y Arias, 1991). 
Cuadro 1

Clasificación petrográfica de las rocas ígneas correspondientes a la Unidad Lohmann y Formación La Cruz (coordenadas E y N en Lambert Sur).

\begin{tabular}{|c|c|c|c|c|c|c|c|c|c|c|c|c|c|c|c|c|}
\hline \multirow{2}{*}{ Código } & \multirow{2}{*}{ Localidad } & \multirow{2}{*}{ E } & \multirow{2}{*}{$\mathrm{N}$} & \multicolumn{5}{|c|}{ Fenocristales } & \multicolumn{6}{|c|}{ Matriz } & \multirow{2}{*}{$O$} & \multirow{2}{*}{ NP } \\
\hline & & & & $\mathrm{p}$ & ol & $\mathrm{cpx}$ & $\mathrm{a}$ & op & $\mathrm{p}$ & ol & $\mathrm{px}$ & $\mathrm{a}$ & $\mathrm{v}$ & op & & \\
\hline $\mathrm{CH} 031677$ & C. Lohmann & 517489 & 373233 & 37 & 1 & 2 & 0 & 1 & 28 & 0 & 16 & 0 & 0 & 13 & 2 & And. \\
\hline E031653 & C. Ena & 521764 & 368596 & 40 & 2 & 0 & 0 & 1 & 24 & 0 & 27 & 0 & 0 & 6 & 0 & And. \\
\hline E031655 & C. Ena & 523001 & 369007 & 30 & 0 & 1 & 0 & 0 & 41 & 0 & 22 & 0 & 0 & 6 & 0 & And. \\
\hline E031661 & C. Ena & 524517 & 369809 & 28 & 0 & 0 & 0 & 1 & 32 & 0 & 4 & 0 & 24 & 11 & 0 & $\begin{array}{l}\text { And. } \\
\text { vít. }\end{array}$ \\
\hline E031667 & C. Ena & 523763 & 368733 & 27 & 7 & 3 & 0 & 1 & 29 & 0 & 24 & 0 & 0 & 3 & 6 & $\begin{array}{l}\text { Bas. } \\
+ \text { oliv. } \\
+ \text { clor. }\end{array}$ \\
\hline CH031686 & C. Nuevo & 518955 & 380982 & 34 & 6 & 0 & 0 & 3 & 26 & 0 & 12 & 0 & 0 & 2 & 17 & $\begin{array}{l}\text { And. } \\
\text { bas. } \\
+ \text { oliv. }\end{array}$ \\
\hline $\mathrm{CH} 031680$ & $\begin{array}{c}\text { S. del } \\
\text { Chirripó }\end{array}$ & 517433 & 377347 & 39 & 7 & 2 & 0 & 2 & 25 & 0 & 14 & 0 & 0 & 9 & 2 & $\begin{array}{l}\text { Bas. } \\
+ \text { oliv. }\end{array}$ \\
\hline $\mathrm{CH} 031688$ & C. Chirripó & 519344 & 381704 & 25 & 0 & 4 & 1 & 1 & $\mathrm{x}$ & 0 & $\mathrm{x}$ & 0 & 0 & $\mathrm{x}$ & $\mathrm{x}$ & $\begin{array}{c}\text { And./ } \\
\text { bas. al- } \\
\text { terado }\end{array}$ \\
\hline ЕСH031693 & Andesita & 591466 & 325662 & 19 & 0 & 0,5 & 0 & 2,5 & 60 & 0 & 0 & 6 & 0 & 8 & 4 & And. \\
\hline P031638 & Biolley & 572059 & 330763 & 19 & 0 & 3 & 1 & 1 & 38 & 0 & 19 & 0 & 0 & 19 & 0 & Bas. \\
\hline P031639B & Fila Pittier & 574530 & 328445 & 33 & 7 & 1 & 0 & 1 & 23 & 0 & 21 & 0 & 0 & 12 & 2 & $\begin{array}{c}\text { Bas. } \\
+ \text { oliv. }\end{array}$ \\
\hline P031643 & Fila Pittier & 578729 & 332514 & 37 & 0 & 0,5 & 0 & 3 & 34 & 0 & 18 & 0 & 0 & 5,5 & 2 & And. \\
\hline C211007 & C. Cuericí & 502206 & 383810 & 31 & 2 & 5 & 0 & 1 & 24 & 0 & 20 & 0 & 0 & 17 & 0 & $\begin{array}{l}\text { Bas. } \\
+ \text { cpx. }\end{array}$ \\
\hline C211001 & C. Cuericí & 498635 & 389441 & 31 & 0 & 4 & 0 & 2 & 50 & 0 & 10 & 0 & 0 & 3 & 0 & And. \\
\hline C211002 & C. Cuericí & 499070 & 389331 & 32 & 0 & 6 & 0 & 2 & 44 & 0 & 10 & 0 & 0 & 6 & 0 & $\begin{array}{l}\text { And. } \\
+ \text { cpx. }\end{array}$ \\
\hline SI031670 & C. Cuericí & 498222 & 388887 & 25 & 1 & 4 & 0 & 5 & 15 & 0 & 0 & 0 & 35 & 15 & 0 & Bas. \\
\hline $\mathrm{C} 031625 \mathrm{~A}$ & C. Cuericí & 500446 & 391027 & 34 & 0 & 2 & 0 & 1 & 34 & 0 & 13 & 0 & 0 & 5 & 11 & And. \\
\hline $\mathrm{C} 031625 \mathrm{~B}$ & C. Cuericí & 500446 & 391027 & 36 & 0 & 7 & 0 & 3 & 16 & 0 & 5 & 0 & 20 & 5 & 8 & $\begin{array}{l}\text { And. } \\
+ \text { cpx. }\end{array}$ \\
\hline $\mathrm{C} 031626$ & C. Cuericí & 500106 & 390774 & 29 & 0 & 7 & 0 & 3 & 42 & 0 & 4 & 0 & 7,5 & 4 & 3,5 & $\begin{array}{l}\text { And. } \\
+ \text { cpx. }\end{array}$ \\
\hline $\mathrm{C} 031627$ & C. Cuericí & 499790 & 390196 & 40 & 0 & 3 & 0 & 2 & 26 & 0 & 17 & 0 & 0 & 12 & 0 & And. \\
\hline $\mathrm{C} 031628$ & C. Cuericí & 499696 & 389931 & 32 & 0 & 16 & 0 & 1 & 25 & 0 & 19 & 0 & 0 & 7 & 0 & $\begin{array}{l}\text { And. } \\
\text { bas. } \\
+ \text { cpx. }\end{array}$ \\
\hline
\end{tabular}


Cuadro 1 (continuación)

Clasificación petrográfica de las rocas ígneas correspondientes a la Unidad Lohmann y Formación La Cruz (coordenadas E y N en Lambert Sur).

\begin{tabular}{|c|c|c|c|c|c|c|c|c|c|c|c|c|c|c|c|c|}
\hline \multirow{2}{*}{ Código } & \multirow{2}{*}{ Localidad } & \multirow{2}{*}{ E } & \multirow{2}{*}{$\mathrm{N}$} & \multicolumn{5}{|c|}{ Fenocristales } & \multicolumn{6}{|c|}{ Matriz } & \multirow{2}{*}{$O$} & \multirow{2}{*}{ NP } \\
\hline & & & & $\mathrm{p}$ & ol & $\mathrm{cpx}$ & $\mathrm{a}$ & op & $\mathrm{p}$ & ol & $\mathrm{px}$ & $\mathrm{a}$ & $\mathrm{v}$ & op & & \\
\hline K031608 & C. Kasir & 566802 & 350378 & 35 & 0 & 3 & 0 & 1 & 40 & 0 & 13 & 0 & 0 & 8 & 0 & And. \\
\hline K031612 & C. Dudu & 564917 & 354304 & 18 & 0 & 5 & 0 & 3 & 3 & 0 & 1 & 0 & 67 & 0 & 3 & $\begin{array}{c}\text { And. } \\
\text { vít. } \\
+\mathrm{cpx}\end{array}$ \\
\hline K031614 & C. Dudu & 564973 & 355781 & 30 & 0 & 1 & 0 & 4 & 37 & 0 & 20 & 0 & 0 & 7 & 1 & And. \\
\hline
\end{tabular}

C.: cerro; NP: nombre petrográfico; p: plagioclasa; ol: olivino; cpx: clinopiroxeno; a: anfíbol; op: opacos, generalmente magnetita; px: piroxeno; v: vidrio o material criptocristalino; o: otros (CH031677: calcita y nontronita; E031667: vesículas rellenas de clorita azul y calcita; CH031686: clorita y glomeropórfidos de plagioclasa y magnetita; CH031680: clorita y calcita principalmente; CH031688: xenolitos y biotita secundaria; ECH031693: epidota; P031639B: vesículas rellenas de clorita azul; C031625A: calcita y epidota; C031625B: epidota, prehnita, calcita, actinolita, clorita azul, clorita parda y leucoxeno; C031626: calcita, pirita y clorita principalmente; K031612: xenolitos andesíticos; K031614: cuarzo). x: mineral observado, proporción difícil de estimar. And.: andesita; Bas.: basalto o basáltico(a); vít.: vítreo; oliv.: olivino; cpx.: clinopiroxeno; clor.: clorita; "+”: "con”.

\section{Génesis}

Denyer y Arias (1991) proponen que las efusiones magmáticas de la Formación La Cruz se originaron en fracturas, y que se trata de productos volcánicos con gran fluidez, lo que explicaría su extensión y espesor. Esto podría ser válido para ambas unidades ígneas pre-intrusivas. Sin embargo, los productos ígneos en el área de estudio podrían corresponder más bien con paleoestratovolcanes extensos y espesos (G. Soto, com. escrita, 2018), con espesores mayores que los esperables en derrames basálticos muy fluidos.

\section{Intrusivo de Talamanca ( $\gamma 2$ ) y stock de Chirripó ( $(3)$}

La presencia de rocas plutónicas en la cordillera de Talamanca es probablemente el rasgo geológico regional que mayor atención ha despertado en la comunidad científica desde el siglo XIX, como lo reflejan las descripciones de Gabb (1874). Hasta la fecha, prácticamente todas las rocas intrusivas de la cordillera se han agrupado en una única denominación, que ha cambiado a través del tiempo (Serie comagmática de Talamanca en Dengo, 1962; Grupo comagmático intrusivo de Talamanca en Berrangé y Whittaker, 1977; Grupo granito-gabro de Talamanca según Kussmaul, 1987). Otras rocas plutónicas más antiguas se han reportado aisladamente en ambas pendientes de la cordillera (Drummond et al., 1995; Abratis, 1998; ver recopilación de Alvarado y Gans, 2012). Futuros trabajos deberán delimitar y caracterizar estar rocas, poco conocidas en la actualidad.

En el presente trabajo se define el Intrusivo de Talamanca como un conjunto de rocas plutónicas de composición predominantemente monzonítica cuarzosa, y en menor proporción monzodiorítica, granítica o gabroica, cuyo emplazamiento tuvo lugar en el Mioceno Medio-Superior y que afloran en distintas localidades distribuidas en todo el conjunto de la cordillera de Talamanca. Su extensión superficial en el área de estudio es $1034 \mathrm{~km}^{2}$; abarca un $19,41 \%$ del territorio dentro del mapa adjunto, por debajo únicamente de las rocas ígneas pre-intrusivas. 


\section{Descripción}

El Intrusivo de Talamanca está constituido fundamentalmente por monzonitas cuarzosas, monzonitas, monzodioritas o monzogabros, granitos y granodioritas hacia los flancos de la cordillera (los sectores de menor altitud) y gabros y dioritas en las partes más altas, por lo general sobre los 2500 m s.n.m. (Alfaro, 2017; Fig. 4). La arenitización es muy frecuente, y es común observar bloques redondeados por meteorización esferoidal, rodeados de subproductos de la arenitización que a veces conservan la textura granular.

Petrográficamente, las rocas intrusivas de Talamanca presentan principalmente plagioclasa, ortosa, cuarzo, anfíbol y clinopiroxeno, como se observa en la figura 5 (Weyl, 1957; Kussmaul, 1987; Abratis, 1998; Gräfe, 1998; Obando y Kussmaul, 2009; Ulloa y Delgado, 2010; Alfaro, 2017). La plagioclasa varía entre andesina y labradorita, y es el feldespato dominante; solo en Tres Colinas (muestras de las coordenadas P11) y Corte Fuentes (C991501, coordenadas B2) se encontraron rocas plutónicas con mayores cantidades de feldespato potásico. El cuarzo rara vez alcanza el 20\% de la muestra (ver cuadro 2).

En cuanto a los minerales ferromagnesianos, la hornblenda verde es el más frecuente, pues aparece en 26 de las 33 muestras analizadas. El clinopiroxeno también puede ser muy abundante $(>10 \%)$, como se observa al oeste del macizo de Kámuk (muestras de las coordenadas P8) y en otras localidades aisladas. El ortopiroxeno rara vez se observa (muestras CH031689, K011009, P031640). La biotita es escasa en todas las muestras excepto en Cedral (coordenadas E6), donde los fenocristales constituyen hasta un $8 \%$ de la masa total de la roca. Los cristales son de menos de $2 \mathrm{~mm}$ de diámetro, aunque dada su abundancia es común observar micas con un brillo amarillo característico en los suelos que rodean los bloques intrusivos. La biotita también constituye una fase mineral de importancia en Tres Colinas (muestra K031624) y en el cerro Echandi (ECH031692). El olivino sólo aparece en la muestra C991505 (4\%), al norte de División (coordenadas B2); se presenta sustituido por magnetita y nontronita.

Debido a que las rocas plutónicas son bastante similares entre sí según el criterio petrográfico, es difícil establecer una separación entre las facies que constituyen el conjunto intrusivo. Aunque el muestreo realizado no fue sistemático con respecto al área (en algunos casos se recolectaron muestras muy próximas entre sí) se advierte que rara vez se observan monzonitas, monzonitas cuarzosas o granitos en las partes altas, y que los gabros son más raros en las partes bajas de la cordillera. Es decir, parece ser que las rocas bajo los $2500 \mathrm{~m}$ s.n.m. son más félsicas y por encima de esta cota son más máficas, o que al menos esa es la tendencia general. Puede que en realidad se trate de varios stocks de unos cuantos kilómetros de diámetro, por lo que sería necesario un modelo por separado para cada uno, y que por tal motivo resulta difícil establecer una división general entre las facies para la totalidad de los intrusivos del Mioceno Medio-Superior. Lo cierto es que, según nuestras investigaciones, las rocas plutónicas son poco frecuentes hacia las cimas de la Talamanca. Entre las siete visitadas solo hay dos que presentan rocas intrusivas: Chirripó (muestra CH031689) y Echandi (ECH031692). Se trata en ambos casos de leucogabros cuarzosos, por lo general con minerales de dimensión máxima inferior a los $2 \mathrm{~mm}$. En los cerros Kámuk y Dúrika se observan algunos intrusivos cerca de las partes de mayor elevación, constituidas por rocas ígneas más recientes.

La separación del stock de Chirripó (Fig. 6) se propone a partir de algunas evidencias petrográficas (Alfaro, 2017), como el predominio de leucogabros cuarzosos, o tonalitas según el criterio geoquímico (Abratis, 1998). Probablemente se trata de un intrusivo más joven, según una datación $\mathrm{K} / \mathrm{Ar}$ de 7,81 $\pm 0,31$ millones de años (De Boer et al., 1995; Drummond et al., 1995). Nuevas dataciones hacen falta para esclarecer esta división. Ya Dengo (1962) había propuesto la existencia de este stock. 


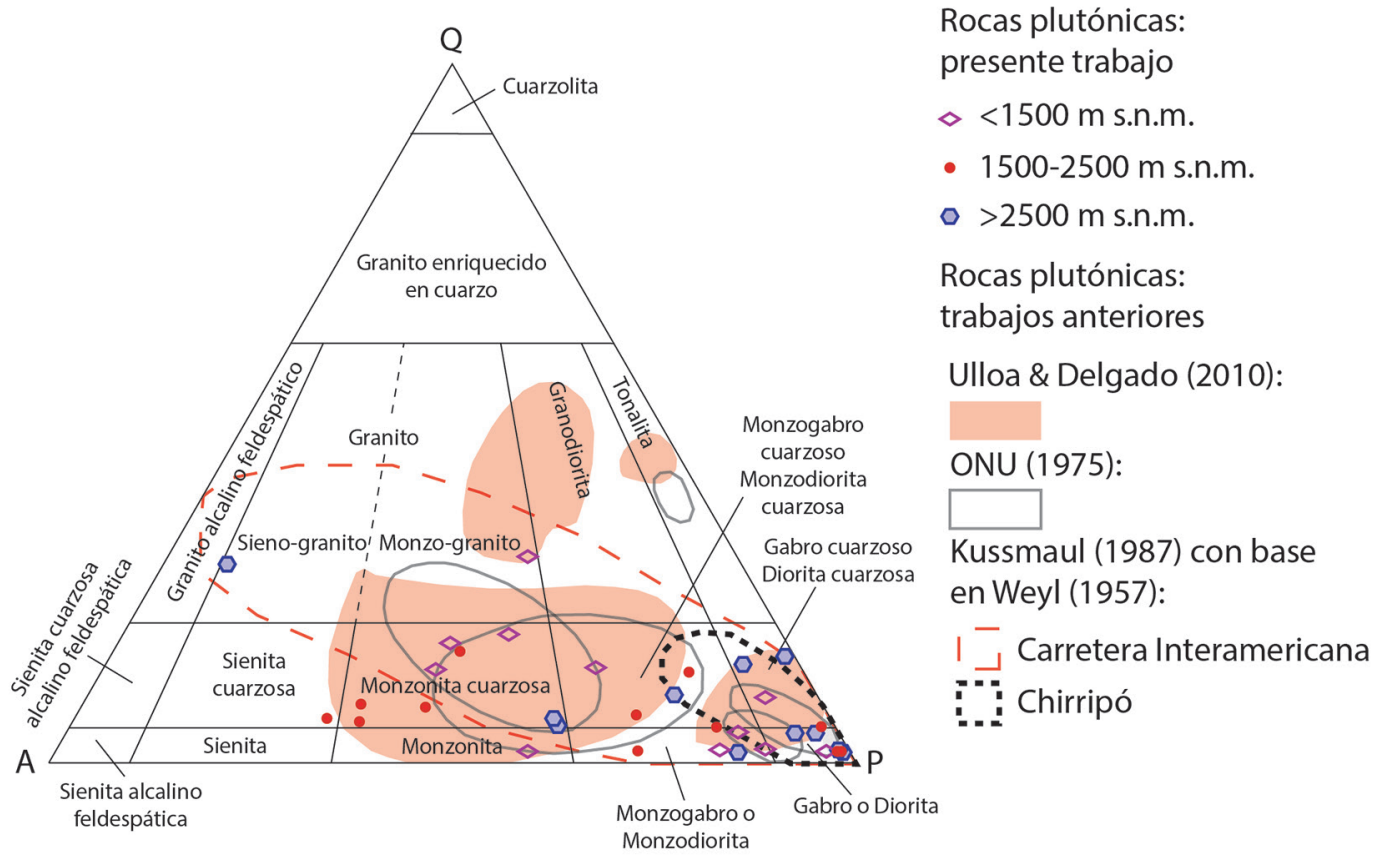

Fig. 4: Distribución de las rocas plutónicas de la cordillera de Talamanca en el diagrama Cuarzo (Q) - Feldespato potásico (A) Plagioclasa $(\mathrm{P})$.

\section{Estratotipo}

En varias localidades a lo largo de la cordillera se observan excelentes exposiciones. Los mejores afloramientos visitados en esta investigación son: Cedral (512364 E, 367728 N), San Gerardo $(506091 \mathrm{E}, 383870 \mathrm{~N})$ y Tres Colinas $(565730 \mathrm{E}$, $341925 \mathrm{~N})$. Sin embargo, es sobresaliente el intrusivo observado al norte de Buenos Aires, uno de los cuerpos ígneos de mayor tamaño en la región (Obando y Kussmaul, 2009; Ulloa y Delgado, 2010), que aflora en un área estimada de 155 $\mathrm{km}^{2}$, según se observa en el mapa adjunto. Ulloa y Delgado (2010) han descrito con detalle este intrusivo, donde sobresalen rocas de composición félsica. Destacan un tajo constituido por granitos (531381 E, $363954 \mathrm{~N})$ y localidades cercanas a Ujarraz, como el tajo en $540886 \mathrm{E}, 345004 \mathrm{~N}$.

El estratotipo del stock de Chirripó es la cima del cerro homónimo (519344 E, 381704 N) donde se observan leucogabros cuarzosos y ocasionalmente algunas andesitas y basaltos con alteración potásica, interpretados aquí como megaxenolitos de la Unidad Lohmann dentro de la masa intrusiva (Fig. 6). En general, las rocas sedimentarias en el macizo se inclinan hacia el SW, aunque localmente se observan sedimentitas con buzamiento $\mathrm{S} 11^{\circ} \mathrm{E} / 31$ (519188 E, 381058 N, cerca del cerro Pirámide).

\section{Distribución geográfica}

Los productos del evento intrusivo del Mioceno Medio-Superior parecen distribuirse en casi todo el ámbito geográfico de la cordillera. Sin embargo, es notable el hecho de que en algunas áreas se pueden recorrer varios kilómetros sin hallar afloramientos intrusivos, especialmente hacia las partes más altas, con excepción de los cerros Chirripó, Echandi y Apri (al oeste del macizo de Kámuk). 
Cuadro 2

Clasificación petrográfica de las rocas intrusivas (coordenadas E y N en Lambert Sur).

\begin{tabular}{|c|c|c|c|c|c|c|c|c|c|c|c|c|}
\hline Código & Localidad & $\mathrm{E}$ & $\mathrm{N}$ & $\mathrm{p}$ & $k-f$ & $\mathrm{qz}$ & $\mathrm{cpx}$ & $\mathrm{a}$ & $\mathrm{b}$ & op & o & Nombre petrográfico \\
\hline K011008 & Cabagra & 551618 & 345004 & 35 & 38 & 11 & 0 & 13 & 1 & 2 & 0 & Monzonita qz. + anf. \\
\hline K011009 & Cabagra & 552100 & 345556 & 43 & 29 & 1 & 4 & 17 & 0 & 5 & 1 & Monzonita + anf. \\
\hline BA30121501 & Buenos Aires & 540886 & 355631 & 37 & 37 & 15 & 0 & 6 & 3 & 2 & 0 & Monzonita qz. + anf. \\
\hline K031624 & Tres Colinas & 565820 & 341726 & 26 & 51 & 5 & 0 & 10 & 5 & 3 & 0 & Sienita qz. + anf. y biot. \\
\hline K031623 & Tres Colinas & 565730 & 341925 & 32 & 52 & 5 & 3 & 0 & 2 & 3 & 3 & Monzonita qz. \\
\hline K031601 & Tres Colinas & 565782 & 343278 & 30 & 49 & 7 & 2 & 6 & 2 & 4 & 0 & Monzonita qz. + anf. \\
\hline K031602 & Tres Colinas & 565768 & 344005 & 28 & 32 & 5 & 0 & 25 & 0 & 8 & 2 & Melamonzonita qz. + anf. \\
\hline K031622 & W. del Kámuk & 567285 & 356642 & 49 & 28 & 5 & 4 & 1 & 4 & 4 & 5 & Monzonita qz. \\
\hline D031707 & C. Akó & 541092 & 368198 & 48 & 27 & 4 & 0 & 9 & 0 & 4 & 8 & Monzonita + anf. y clor. \\
\hline $\mathrm{C} 211003$ & Buenavista & 500853 & 386243 & 53 & 18 & 5 & 14 & 3 & 3 & 4 & 0 & Mnzgab. qz. \\
\hline $\mathrm{C} 211004$ & Buenavista & 500983 & 386419 & 66 & 12 & 4 & 0 & 15 & 0 & 3 & 0 & Mnzdior. qz. + anf. \\
\hline C211004A & Buenavista & 500983 & 386419 & 50 & 18 & 0 & 0 & 25 & 0 & 7 & 0 & Mnzdior. + anf. \\
\hline $\mathrm{C} 211006$ & Buenavista & 500722 & 383280 & 40 & 23 & 26 & 0 & 8 & 0 & 3 & 0 & Granito + anf. \\
\hline $\mathrm{C} 211008$ & Buenavista & 502540 & 383922 & 52 & 10 & 9 & 4 & 19 & 0 & 6 & 0 & Mnzgab. qz. + anf. \\
\hline SI221003 & Cedral & 512364 & 367728 & 52 & 6 & 1 & 14 & 17 & 8 & 2 & 0 & Mnzdior. + anf. y biot. \\
\hline SI221007 & Cedral & 512575 & 368818 & 61 & 9 & 3 & 6 & 11 & 7 & 3 & 0 & Mnzdior. + anf. y biot. \\
\hline SI031671 & San Jerónimo & 517480 & 367095 & 40 & 28 & 15 & 0 & 11 & 0 & 3 & 3 & Monzonita qz. + anf. \\
\hline K011002 & C. Pelón & 549169 & 349153 & 52 & 10 & 0 & 0 & 28 & 0 & 10 & 0 & Mnzgab. + anf. \\
\hline S1091501 & San Gerardo & 506763 & 379151 & 46 & 19 & 10 & 1 & 19 & 3 & 2 & 0 & Mnzgab. qz. + anf. y biot. \\
\hline C1091503 & San Gerardo & 506091 & 383870 & 36 & 34 & 13 & 0 & 6 & 2 & 3 & 6 & Monzonita qz. + anf. \\
\hline C991503 & $\begin{array}{l}\text { Ca. Intera- } \\
\text { mericana }\end{array}$ & 495882 & 387367 & 54 & 13 & 7 & 3 & 5 & 3 & 5 & 10 & $\begin{array}{l}\text { Mnzgab. qz. + biot. y } \\
\text { anf. }\end{array}$ \\
\hline C991505 & $\begin{array}{l}\text { Ca. Intera- } \\
\text { mericana }\end{array}$ & 495502 & 385948 & 69 & 0 & 0 & 21 & 1 & 2 & 3 & 4 & Leucogabro \\
\hline C991508 & $\begin{array}{l}\text { Ca. Intera- } \\
\text { mericana }\end{array}$ & 499600 & 384126 & 65 & 5 & 7 & 8 & 10 & 0 & 4 & 1 & Leucogabro qz. + anf. \\
\hline SI031674 & San Jerónimo & 517480 & 367095 & 69 & 2 & 0 & 13 & 11 & 0 & 5 & 0 & Gabro + anf. \\
\hline K031615 & C. Apri & 566286 & 356374 & 68 & 11 & 1 & 15 & 0 & 1 & 4 & 0 & Leucomonzogabro \\
\hline K031616 & C. Apri & 566430 & 356408 & 62 & 0 & 0 & 27 & 0 & 1 & 10 & 0 & Gabro \\
\hline K031617 & C. Apri & 567185 & 356608 & 70 & 0 & 1 & 19 & 0 & 0 & 6 & 4 & Leucogabro \\
\hline P031640 & Fila Pittier & 577409 & 331945 & 57 & 0 & 3 & 22 & 0 & 0 & 16 & 2 & Gabro qz. + clor. \\
\hline ECH031692 & C. Echandi & 593072 & 331580 & 73 & 0 & 13 & 2 & 4 & 4 & 4 & 0 & Leucogabro qz. \\
\hline CH031689 & C. Chirripó & 519344 & 381704 & 69 & 6 & 12 & 1 & 6 & 0 & 5 & 1 & Leucogabro qz. + anf. \\
\hline
\end{tabular}


Cuadro 2 (continuación)

Clasificación petrográfica de las rocas intrusivas (coordenadas E y N en Lambert Sur).

\begin{tabular}{ccccccccccccc}
\hline Código & Localidad & $\mathrm{E}$ & $\mathrm{N}$ & $\mathrm{p}$ & $\mathrm{k}-\mathrm{f}$ & $\mathrm{qz}$ & $\mathrm{cpx}$ & $\mathrm{a}$ & $\mathrm{b}$ & $\mathrm{op}$ & $\mathrm{o}$ & Nombre petrográfico \\
\hline CH031682 & $\begin{array}{c}\text { SW del } \\
\text { Chirripó }\end{array}$ & 517410 & 380410 & 68 & 4 & 3 & 11 & 0 & 0 & 5 & 9 & Leucogabro \\
CH031683 & $\begin{array}{c}\text { SW del } \\
\text { Chirripó }\end{array}$ & 517969 & 380395 & 68 & 2 & 3 & 8 & 5 & 0 & 6 & 8 & Gabro + anf. \\
& $\begin{array}{c}\text { Corte Fuentes } \\
\text { C991501 }\end{array}$ & 494823 & 388297 & 8 & 61 & 27 & 0 & 0 & 0 & 4 & 0 & Aplita \\
\hline
\end{tabular}

C.: cerro; Ca.: Carretera; p: plagioclasa; k-f: feldespato potásico (ortosa); qz: cuarzo o cuarzoso(a); cpx: clinopiroxeno; a: anfíbol; op: opacos; o: otros (K011009: ortopiroxeno; K031623: clorita y epidota; K031602: epidota; K031622: clorita y epidota; D031707: clorita y epidota; SI031671: clorita azul; C1091503: clorita parda; C991503: clorita; C991505: olivino; C991508: clorita; K031617: clorita; P031640: ortopiroxeno; CH031689: ortopiroxeno; CH031682: fantasmas de ferromagnesiano y actinolita; CH031683: fantasmas de ferromagnesiano). 1 C991501: fantasmas de ferromagnesiano; ${ }^{1} \mathrm{C} 991501$ : turmalina de tipo schorlita en menos de $1 \%$. Mnzgab.: monzogabro; Mnzdior.: monzodiorita; qz.: cuarzoso(a); anf.: anfíbol; biot.: biotita; clor.: clorita; “+”: "con”

\section{Edad y correlaciones}

Una serie de 41 dataciones radiométricas indican que las rocas intrusivas de Talamanca varían entre 12,5 y 7,5 millones de años (Berrangé y Whittaker, 1977; Bellon y Tournon, 1978; Bergoeing, 1982; De Boer et al., 1995; Drummond et al., 1995; Gräfe, 1998; Gräfe et al., 2002; MacMillan et al., 2004), salvo algunas excepciones (ver Alvarado y Gans, 2012). Solo 9 de estas dataciones son ${ }^{40} \mathrm{Ar} /{ }^{39} \mathrm{Ar}$, y de estas ninguna es de edad superior a los 11,70 millones de años (MacMillan et al., 2004). Del total de dataciones, 9 corresponden con el intrusivo del norte de Buenos Aires, con edades restringidas a 10,5-9,8 millones de años aproximadamente. Dentro del área de estudio hay 6 dataciones ${ }^{40} \mathrm{Ar} /{ }^{39} \mathrm{Ar}$ de rocas intrusivas, tal y como se especifica en el mapa adjunto.

\section{Génesis}

De acuerdo con Drummond et al. (1995) se trata de intrusiones epizonales (de baja temperatura), emplazadas a $<1 \mathrm{kbar}$, a $805-860^{\circ} \mathrm{C}$. La profundidad de emplazamiento se estima entre 3 y $5 \mathrm{~km}$ (Gräfe, 1998). Análisis del enfriamiento de minerales indican que el intrusivo en el cerro Chirripó se enfrió a una temperatura $100^{\circ} \mathrm{C}$ más alta que el resto de los intrusivos (Gräfe, 1998).

\section{Rocas ígneas post-intrusivas}

Para las rocas ígneas volcánicas o subvolcánicas más jóvenes que 10 millones de años, los criterios de diferenciación petrográfica entre las unidades definidas son principalmente los minerales ferrogmanesianos. La presencia de ortopiroxeno (Gazel et al., 2009) se ha considerado un aspecto que permite identificar rocas ígneas posteriores al Intrusivo de Talamanca, conocidas para la región axial de la cordillera como Unidad Kámuk, mientras que la biotita es frecuente en rocas que conforman un grupo bien definido con tendencia alcalina, denominado Unidad Dúrika (ver figura 7).

En conjunto, las rocas ígneas post-intrusivas ocupan un $6,95 \%$ del área dentro del mapa adjunto. La Unidad Kámuk representa un 0,51\%, la Unidad Dúrika un 0,49\% y la Unidad Río Lori un 
$0,15 \%$. Las formaciones Paso Real $(2,59 \%)$ hacia la fila Costeña y Suretka $(1,15 \%)$ en Baja Talamanca, además de los flujos de dacitas y andesitas al sureste $(2,06 \%)$, representan la fracción restante.

\section{Unidad Kámuk (a3)}

La Unidad Kámuk es un grupo de rocas de composición intermedia, en que predominan fenocristales de plagioclasa (5-45\%) y clinopiroxeno $(0-23 \%)$, en una matriz por lo general intergranular. En sección delgada puede observarse el ortopiroxeno (0-5\%), aunque no en todas las muestras. En tales casos, el criterio geoquímico ha sido necesario: la Unidad Kámuk pertenece a series con alto $\mathrm{K}$, con $\mathrm{La} / \mathrm{Yb}$ entre 10 y 20 . Las rocas pre-intrusivas, por su parte, son de bajo $\mathrm{K}$, con $\mathrm{La} / \mathrm{Yb}<10$ (Alfaro, 2017).

\section{Descripción}

La Unidad Kámuk está constituida fundamentalmente por andesitas y andesitas basálticas, aunque también hay dacitas que se asocian con este grupo. En todos los casos la textura es afanítica porfirítica; a simple vista sobresalen fenocristales de plagioclasa, rodeados de una matriz gris en donde se observan minerales ferromagnesianos, principalmente clinopiroxenos. El ortopiroxeno es un buen indicador de esta unidad (ver cuadro 3). Ya Gazel et al. (2009), con base en dataciones y observaciones petrográficas, habían afirmado que el ortopiroxeno aparece como fenocristal durante el Mioceno Superior, lo que se ajusta a las edades propuestas para la Formación Grifo Alto (Alvarado y Gans, 2012), que varían entre 7,30 y 3,50 millones de años según dataciones ${ }^{40} \mathrm{Ar} /{ }^{39} \mathrm{Ar}$.

La paragénesis típica de la Unidad Kámuk es plagioclasa de tipo labradorita, clinopiroxeno, ortopiroxeno y magnetita. El ortopiroxeno puede presentarse en núcleos ya alterados a clorita o calcita, con bordes de clinopiroxeno (textura en corona). El olivino es poco frecuente y aparece alterado a serpentinita u óxidos de hierro. Algunas muestras contienen anfíboles. La proporción de fenocristales (14-66\%) es en general más alta que en las rocas pre-intrusivas $(22-50 \%)$. La matriz es intergranular o hialopilítica, con microlitos de plagioclasa, clinopiroxeno y magnetita, y a veces con mucho vidrio o material criptocristalino.

\section{Estratotipo}

El estratotipo se ubica en la cima del cerro Kámuk (569491 E, 358111 N) donde la roca presenta fenocristales de plagioclasa que alcanzan los $10,0 \times 3,0 \mathrm{~mm}$. A lo largo del sendero entre el páramo y la cima se observan buenas exposiciones del macizo rocoso. La roca es masiva y presenta varios sistemas de fracturas (Alfaro, 2017); no se observan diaclasas columnares.

\section{Distribución geográfica}

Además de los afloramientos en el macizo de Kámuk, la unidad aflora en los cerros Cuericí, Ventisqueros y Echandi, además de la fila Pittier.

\section{Edad y correlaciones}

La Unidad Kámuk se considera un equivalente en la cordillera de Talamanca de la Formación Grifo Alto, definida por Denyer y Arias (1991) al sur del Valle Central; esto debido a la similitud en sus características petrográficas, particularmente por la presencia de ortopiroxeno. Si esta correlación es correcta, la Unidad Kámuk no debería tener una edad anterior al Mioceno Superior cuspidal o Plioceno. 


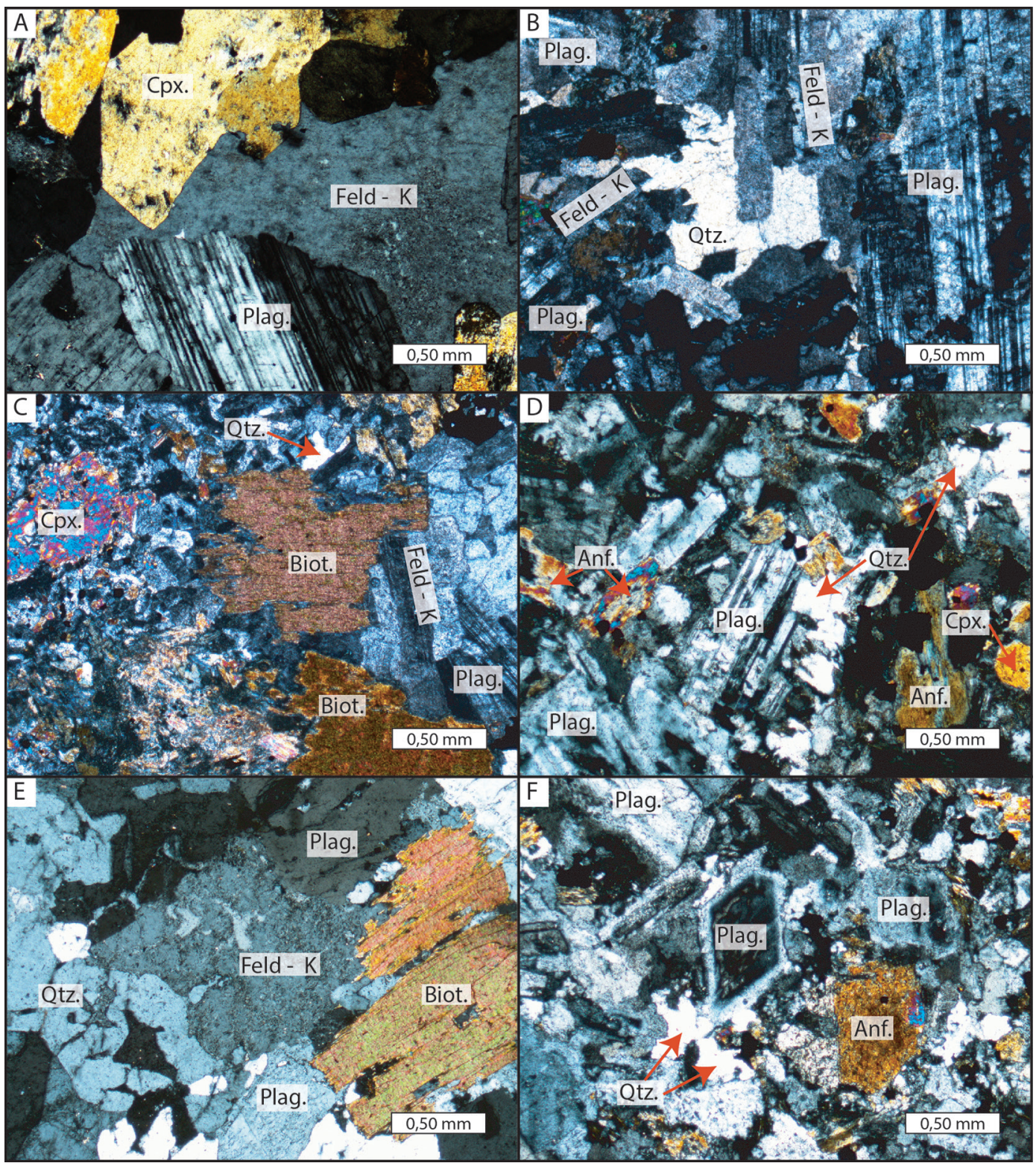

Fig. 5: Rocas intrusivas: A. Monzogabro cuarzoso con hornblenda verde y biotita cloritizada (S1091501), San Gerardo de Pérez Zeledón; B. Monzonita cuarzosa (K031622), entre los cerros Apri y Kámuk; C. Sienita cuarzosa con anfíbol y biotita (K031624) de Tres Colinas; D. Leucogabro cuarzoso (ECH031692), bloque de la cima del cerro Echandi; E. Monzonita cuarzosa (BA30121501) de Ujarraz, al norte de Buenos Aires; F. Leucogabro cuarzoso con anfíbol (CH031689), cima del cerro Chirripó. Plag.: plagioclasa; K-feld.: feldespato potásico; Qtz.: cuarzo; Biot.: biotita; Anf.: anfíbol; Cpx.: clinopiroxeno. 


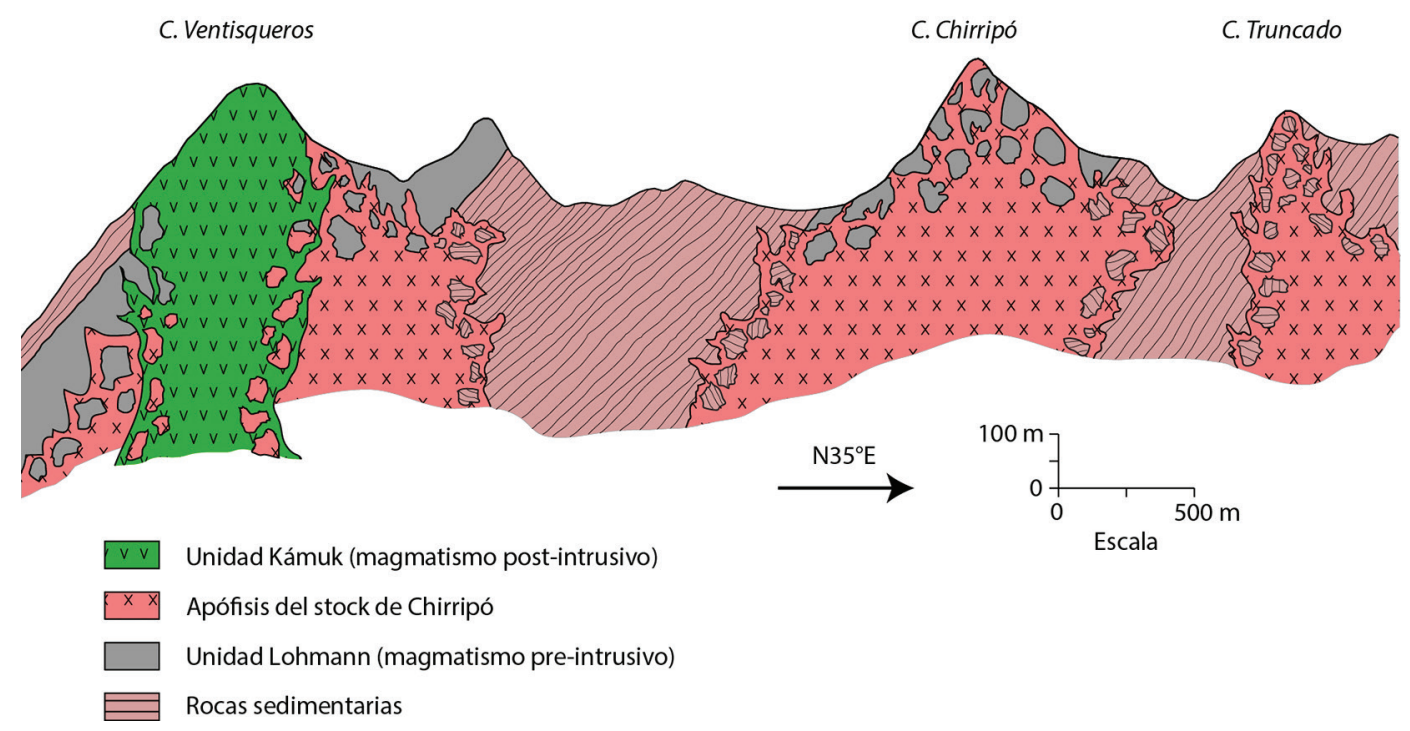

Fig. 6: Perfil esquemático del cerro Chirripó.

\section{Génesis}

Es posible que las rocas de la Unidad Kámuk que afloran en los sectores más elevados de la cordillera sean subvolcánicas (Fig. 8). Resulta difícil considerar rocas volcánicas de 5-6 millones de años o menos hacia las partes altas, dado que el levantamiento y erosión subsecuente de la cordillera habrían removido ya gran parte los productos del vulcanismo. En este trabajo consideramos que en su mayoría son estructuras subvolcánicas las que han sobrevivido a la denudación. Gräfe (1998) estima una tasa de exhumación de 1,4 $\pm 0,5 \mathrm{~km} / \mathrm{Ma}$ (kilómetros cada millón de años) para la cordillera de Talamanca; es probable que las rocas volcánicas del Mioceno Superior y Plioceno ya se hayan erosionado, a no ser que hubiesen experimentado una subsidencia posterior a su emplazamiento.

En el caso del Kámuk, se sugiere que el Intrusivo de Talamanca constituye la mayor proporción del macizo, pero no su cima absoluta (Fig. 8). La cima se interpreta como un criptodomo, es decir, un cuerpo magmático acumulado cerca de la superficie sin llegar a aflorar. Las irregularidades en torno a la cima podrían ser también explicadas mediante la idea de los criptodomos. Gabb (1874, pág. 106) ya había sugerido algo similar:

\begin{abstract}
"Esta cima completa, de más de media milla de largo y cerca de un cuarto de milla de ancho en su base, está compuesta por un dique de una roca porfirítica de color gris amarillento, la cual contiene pequeños cristales de un mineral oscuro, probablemente augita. Esta roca es un dique proyectándose sobre el granito, que ha sobrevivido a la denudación de una roca más suave y fácil de desintegrar".
\end{abstract}

Debe aclararse que en la presente investigación no se observaron rocas intrusivas por encima de los 3180 m s.n.m. en el Kámuk, pero no se descarta su existencia. La descripción litológica de Gabb coincide con los bloques andesíticos meteorizados que se observan sobre la cima del cerro.

\section{Unidad Dúrika ( $\beta 4)$}

Se han agrupado bajo la denominación Unidad Dúrika las latitas que afloran en los alrededores de los cerros Dúrika y Utyum, que son las únicas rocas silíceas con tendencia alcalina en la cordillera de Talamanca. Alfaro (2017) denomina 


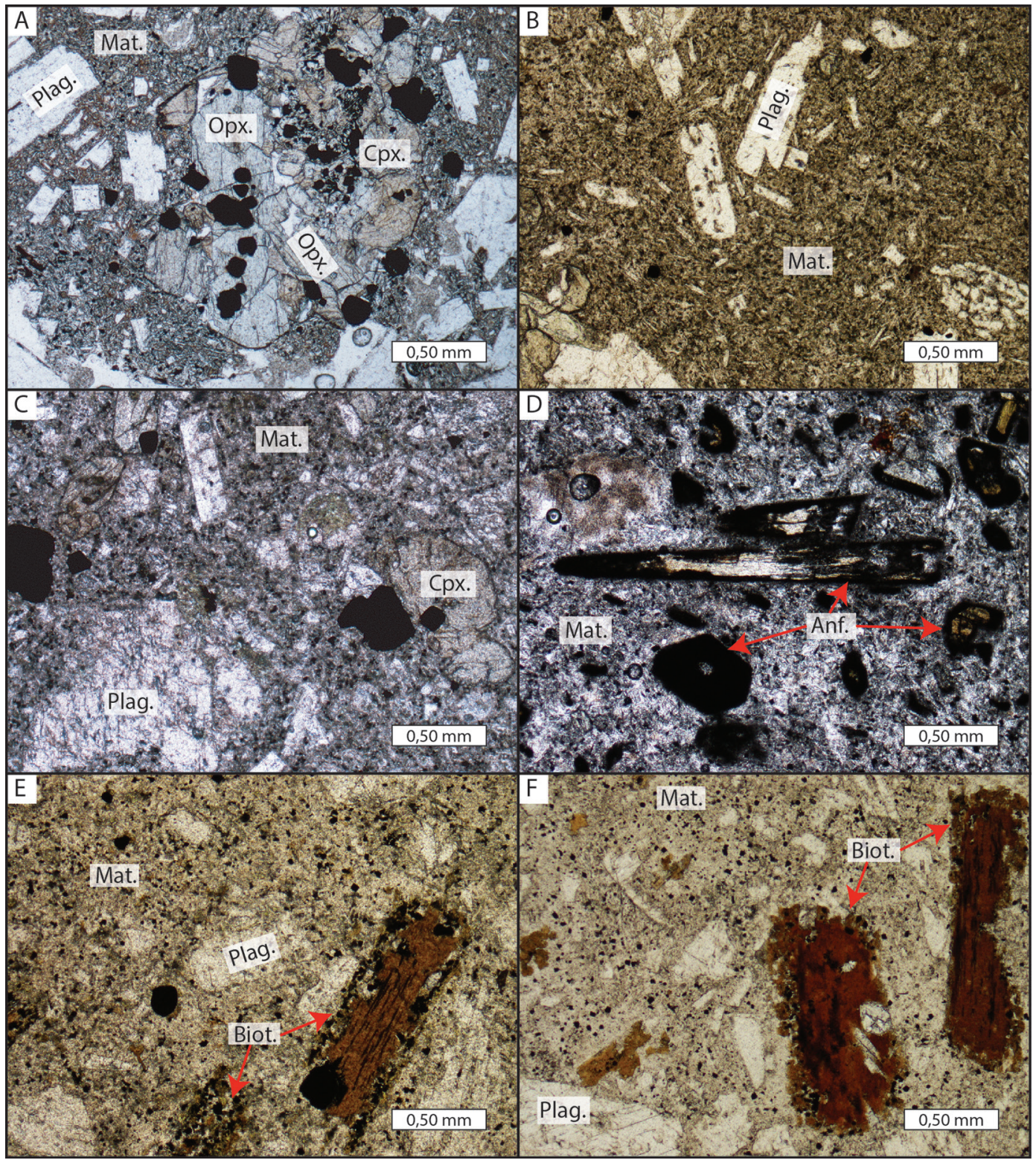

Fig. 7: Rocas volcánicas o hipoabisales de la cordillera de Talamanca: A. Andesita (C031637), bloque de los cerros Cuericí; B. Andesita (CH031681), del cerro Ventisqueros; C. Andesita con clinopiroxeno (K031620), de la cima del cerro Kámuk; D. Dacita con hornblenda basáltica (P031642), muestra de la fila Pittier; E. Latita (D031705) del cerro Surí; F. Latita biotítica (D031706) del cerro Akó. Plag.: plagioclasa; Opx.: ortopiroxeno; Cpx.: clinopiroxeno; Anf.: anfíbol; Biot.: biotita; Mat.: matriz.

estas rocas andesitas con biotita; no obstante, en este trabajo se prefiere la denominación petrográfica de "latita" por cumplir con sus características típicas (plagioclasa de tipo andesina, biotita como mineral ferromagnesiano principal y presencia de feldespato potásico). 
Cuadro 3

Clasificación petrográfica de las rocas ígneas de la Unidad Kámuk (coordenadas E y N en Lambert Sur)

\begin{tabular}{|c|c|c|c|c|c|c|c|c|c|c|c|c|c|c|c|c|}
\hline \multirow{2}{*}{ Código } & \multirow{2}{*}{ Localidad } & \multirow{2}{*}{ E } & \multirow{2}{*}{$\mathrm{N}$} & \multicolumn{6}{|c|}{ Fenocristales } & \multicolumn{5}{|c|}{ Matriz } & \multirow{2}{*}{$O$} & \multirow{2}{*}{ NP } \\
\hline & & & & $\mathrm{p}$ & $\mathrm{ol}$ & opx & $\operatorname{cpx}$ & $\mathrm{a}$ & op & $\mathrm{p}$ & $\mathrm{px}$ & $\mathrm{a}$ & $\mathrm{v}$ & op & & \\
\hline K031604 & C. Bekom & 566096 & 347505 & 33 & 0 & 4 & 12 & 0 & 4 & 20 & 10 & 0 & 9 & 8 & 0 & $\begin{array}{l}\text { And. } \\
\text { vít. + } \\
\text { cpx. }\end{array}$ \\
\hline K031610 & C. Nai & 565597 & 351558 & 24 & 0 & 5 & 7 & 1 & 2 & 38 & 2 & 0 & 18 & 3 & 0 & $\begin{array}{c}\text { And. } \\
\text { vít. + } \\
\text { px. }\end{array}$ \\
\hline K031618 & $\begin{array}{l}\text { SW del } \\
\text { Kámuk }\end{array}$ & 567753 & 357085 & 45 & 0 & 0 & 4 & 0 & 13 & 25 & 3 & 0 & 0 & 9 & 1 & And. \\
\hline K031620 & C. Kámuk & 569491 & 358111 & 42 & 0 & 0 & 10 & 0 & 5 & 24 & 11 & 0 & 0 & 8 & 0 & $\begin{array}{c}\text { And. + } \\
\text { cpx. }\end{array}$ \\
\hline K031621 & $\begin{array}{l}\text { SW del } \\
\text { Kámuk }\end{array}$ & 568454 & 357329 & 34 & 0 & 0 & 6 & 0 & 4 & 34 & 11 & 0 & 0 & 10 & 1 & $\begin{array}{c}\text { And. + } \\
\text { cpx. }\end{array}$ \\
\hline SI221005 & Cedral & 512364 & 367728 & 10 & 0 & 0 & 0 & $3^{1}$ & 1 & 37 & 0 & 36 & 0 & 13 & 0 & $\begin{array}{c}\text { Dq. } \\
\text { (and. + } \\
\text { anf.) }\end{array}$ \\
\hline CH031681 & $\begin{array}{l}\text { C. Ventis- } \\
\text { queros }\end{array}$ & 516969 & 380755 & 11 & 0 & 1 & 1 & 1 & 3 & 59 & 6 & 0 & 0 & 4 & 14 & And. \\
\hline C031637 & C. Cuericí & 503365 & 392300 & 42 & 0 & 4 & 1 & 0 & 2 & 29 & 2 & 0 & 19 & 1 & 0 & $\begin{array}{c}\text { And. + } \\
\text { opx. }\end{array}$ \\
\hline C031636 & C. Cuericí & 503785 & 391884 & 39 & 0 & 0 & 15 & 0 & 3 & 26 & 7 & 0 & 7 & 3 & 0 & $\begin{array}{c}\text { Dq. } \\
\text { (bas. }+ \\
\text { cpx.) }\end{array}$ \\
\hline P031642 & Fila Pittier & 578210 & 332223 & 5 & 0 & 0 & 5 & $10^{2}$ & 0 & 66 & 6 & 2,5 & 0 & 4 & 1,5 & $\begin{array}{c}\text { Dac. }+ \\
\text { anf. }\end{array}$ \\
\hline ЕCH031691 & C. Echandi & 593536 & 330407 & 21 & 0 & 3 & 23 & 0 & 0 & 43 & 3 & 0 & 0 & 6 & 1 & And. \\
\hline E031664 & C. Ena & 524945 & 369278 & 40 & 0 & 1 & 19 & 0 & 1 & 15 & 17 & 0 & 0 & 7 & 0 & $\begin{array}{c}\text { And. } \\
\text { bas. }+ \\
\text { cpx. }\end{array}$ \\
\hline C031629 & C. Cuericí & 500083 & 391325 & 29 & 2 & 1 & 14 & 0 & 4 & $\mathrm{x}$ & $\mathrm{x}$ & 0 & $\mathrm{x}$ & $\mathrm{x}$ & 0 & $\begin{array}{c}\text { And. + } \\
\text { cpx. }\end{array}$ \\
\hline C031630 & C. Cuericí & 500198 & 391693 & 34 & 2 & 0 & 13 & 0 & 5 & 4 & 1 & 0 & 28 & 13 & 0 & $\begin{array}{l}\text { And.+ } \\
\text { cpx. }\end{array}$ \\
\hline C031631 & C. Cuericí & 500221 & 391709 & 36 & 1 & 2 & 13 & 0 & 3 & 12 & 1 & 0 & 30 & 2 & 0 & $\begin{array}{c}\text { And. }+ \\
\text { cpx. }\end{array}$ \\
\hline
\end{tabular}

\section{Descripción}

La Unidad Dúrika se define como un grupo de rocas ígneas con textura afanítica porfirítica, de color gris oscuro a gris claro. La plagioclasa (34-70\%) es de tipo andesina (contenido de anortita de $32,5-45,5 \%)$. La biotita es el mineral ferromagnesiano más sobresaliente (hasta 3,5 x 3,0 $\mathrm{mm}$ ) y presente en mayor proporción (1-5\%). A simple vista es fácilmente determinable por su brillo perlado característico, y en sección delgada tiende a mostrarse en cortes hipidiomórficos a idiomórficos hexagonales muy límpidos; parece ser de formación posterior a la plagioclasa, y en algunos casos se observan cristales con deformación plástica. 
Cuadro 3 (continuación)

Clasificación petrográfica de las rocas ígneas de la Unidad Kámuk (coordenadas E y N en Lambert Sur)

\begin{tabular}{|c|c|c|c|c|c|c|c|c|c|c|c|c|c|c|c|c|}
\hline \multirow{2}{*}{ Código } & \multirow{2}{*}{ Localidad } & \multirow{2}{*}{$\mathrm{E}$} & \multirow{2}{*}{$\mathrm{N}$} & \multicolumn{6}{|c|}{ Fenocristales } & \multicolumn{5}{|c|}{ Matriz } & \multirow{2}{*}{$O$} & \multirow{2}{*}{ NP } \\
\hline & & & & $\mathrm{p}$ & ol & opx & cpx & $\mathrm{a}$ & op & $\mathrm{p}$ & $\mathrm{px}$ & $\mathrm{a}$ & $\mathrm{v}$ & op & & \\
\hline $\mathrm{C} 031632$ & C. Cuericí & 501951 & 392748 & 29 & 0 & 0 & 0 & 0 & 4 & $\mathrm{x}$ & 0 & 0 & 0 & $\mathrm{x}$ & 14 & $\begin{array}{l}\text { And. } \\
\text { al- } \\
\text { terada }\end{array}$ \\
\hline C031633 & C. Cuericí & 502384 & 392527 & 27 & 0 & 3 & 7 & 0 & 3 & 41 & 11 & 0 & 4 & 4 & 0 & Dia. \\
\hline C211005 & $\begin{array}{l}\text { Finca } \\
\text { Alaska }\end{array}$ & 499926 & 385529 & 26 & 4 & 1 & 5 & 0 & 2 & 25 & 22 & 0 & 0 & 15 & 0 & $\begin{array}{c}\text { Bas. + } \\
\text { cpx. }\end{array}$ \\
\hline
\end{tabular}

C.: cerro; p: plagioclasa; ol: olivino; opx: ortopiroxeno; cpx: clinopiroxeno; a: anfíbol; op: opacos; px: piroxenos (sin distinción); v: vidrio o material criptocristalino; o: otros (K031618: ortopiroxeno y xenolitos andesíticos; K031621: ortopiroxeno y circón; CH031681: glomeropórfidos de composición gabroica; P031642: xenocristales de cuarzo en 1\% y fenocristales de biotita en 0,5\%; C031632: calcita, clorita azul y ceolitas). x: mineral observado, proporción difícil de estimar; bas: basáltico; ${ }^{1}$ SI221005: el anfíbol es hornblenda verde; ${ }^{2} \mathrm{P} 031642$ : el anfíbol es hornblenda basáltica.

And.: andesita; Bas.: basalto o basáltico(a); Dac.: dacita; Dia.: diabasa; Dq.: dique; vít.: vítreo(a); px.: piroxenos; opx.: ortopiroxeno; cpx.: clinopiroxeno; anf.: anfíbol; “+”: "con”

Otros componentes de las latitas de la Unidad Dúrika son feldespato potásico (posiblemente anortoclasa, $0-11 \%)$, piroxeno $(0-3 \%)$ y anfíbol (0-2\%). La matriz puede ser muy cristalina o vítrea (ver cuadro 4). Hay evidencias de mezcla de magmas, como en el caso de la muestra U031701 (coordenadas M7, cima del Utyum), donde la sección delgada presenta sectores de constitución latítica, como la Unidad Dúrika, y andesítica, como la Unidad Kámuk. Es probable, por tanto, que ambas unidades hayan coexistido.

Geoquímicamente la Unidad Dúrika se distingue por su alto contenido de potasio $\left(\mathrm{K}_{2} \mathrm{O}\right.$ entre 4,0 y 4,5\%), enriquecimiento en tierras raras livianas, $\mathrm{La} / \mathrm{Yb}>20$ y Nb > 15 ppm (Alfaro, 2017).

\section{Estratotipo}

El estratotipo de esta unidad se localiza en la cima del cerro Dúrika (539582 E, 369692 N). En este sector se pueden observar rocas con características correspondientes a la unidad a lo largo de unos $900 \mathrm{~m}$. Destaca el carácter fanerítico de la roca hacia la parte más alta del cerro; si bien se observa una matriz en sección delgada, esta se encuentra limitada y es difícil separarla de la fracción de fenocristales (muestra D031608, coordenadas J6 en el mapa adjunto).

\section{Distribución geográfica}

Rocas afaníticas porfiríticas con biotita se observan en las tres cimas del Dúrika (cerca de los 3280 m s.n.m.). También están presentes en los cerros Aká y Surí (hoja topográfica Dúrika), y hacia la parte superior de los cerros Utyum (hoja topográfica Kámuk). Tanto Abratis (1998) con la muestra TAL-103, como Ulloa y Delgado (2010) con la muestra $19 \mathrm{~F}-8$, habrían hallado rocas con rasgos similares en las laderas norte y sur de la fila que enlaza las cimas de Dúrika y Utyum (Alfaro, 2017).

Se han observado rocas con características similares a las de la Unidad Dúrika en los cerros de Escazú, particularmente en el cerro Cedral (Barrantes, 1991). No es claro si en esa localidad las rocas son volcánicas o subvolcánicas.

\section{Edad y correlaciones}

No hay dataciones disponibles sobre esta unidad. Es probable una edad más reciente que 10 millones de años, dado el enriquecimiento en tierras raras livianas que presenta la unidad (Alfaro, 2017). Debido a la mezcla de magmas evidenciada en la muestra U031701, se propone una edad muy similar a la de la Unidad Kámuk (Mioceno Superior cuspidal a Plioceno). 


\section{Cuadro 4}

Clasificación petrográfica de las rocas ígneas de la Unidad Dúrika (coordenadas E y N en Lambert Sur).

\begin{tabular}{|c|c|c|c|c|c|c|c|c|c|c|c|c|c|c|c|c|c|c|}
\hline \multirow{2}{*}{ Código } & \multirow{2}{*}{ Localidad } & & \multirow[t]{2}{*}{ N } & \multicolumn{8}{|c|}{ Fenocristales } & \multicolumn{5}{|c|}{ Matriz } & \multirow{2}{*}{ b } & \multirow{2}{*}{ NP } \\
\hline & & & & $\mathrm{p}$ & $k-f$ & $\mathrm{qz}$ & opx & cpx & $\mathrm{a}$ & $\mathrm{b}$ & op & $\mathrm{p}$ & $\mathrm{px}$ & $\mathrm{b}$ & $\mathrm{v}$ & op & & \\
\hline U031701 & C. Utyum & 553271 & 364236 & 36 & 0 & 0 & 0 & 1 & 1 & 2 & $J$ & 12 & 4 & 0 & 31 & 6 & 4 & Lat. \\
\hline U031702 & C. Utyum & 552776 & 362092 & 34 & 0 & 0 & 0 & 0 & 2 & 1 & 2 & $\mathrm{x}$ & $\mathrm{x}$ & 0 & $\mathrm{x}$ & $\mathrm{x}$ & 0 & Lat. \\
\hline D031705 & C. Surí & 541586 & 367236 & 55 & 4 & 0 & 0 & 2 & 0 & 2 & 3 & $26^{1}$ & 0 & 3 & 0 & 5 & 0 & Lat. \\
\hline D031706 & C. Surí & 541170 & 368015 & 62 & 5 & 1 & 1 & 1 & 0 & 5 & 2 & $19^{1}$ & 0 & 1 & 0 & 3 & 0 & Lat. \\
\hline D031708 & C. Dúrika & 539085 & 369972 & 70 & 11 & 1 & 0 & 1 & 1 & 3 & 9 & $0^{2}$ & 0 & 0 & 0 & 0 & 4 & Lat. \\
\hline D031710 & C. Dúrika & 539978 & 369287 & 41 & 0 & 0 & 2 & 3 & 2 & 0 & 3 & 27 & 1 & 0 & 4 & 2 & 15 & And \\
\hline D031711 & C. Dúrika & 539985 & 369274 & 39 & 0 & 0 & 0 & 1 & 1 & 2 & 2 & 5 & 3 & 0 & 45 & 1 & 1 & Lat. \\
\hline
\end{tabular}

C.: cerro; NP: nombre pretrogáfico; p: plagioclasa; k-f: feldespato potásico (anortoclasa); qz: cuarzo; opx: ortopiroxeno; cpx: clinopiroxeno; a: anfíbol; b: biotita; op: opacos; v: vidrio o material criptocristalino; o: otros (U031701: ferromagnesianos no determinables; D031708: calcita y xenolito plutónico; D031710: vesículas; D031711: ferromagnesianos alterados, posiblemente olivino). x: mineral observado, proporción difícil de estimar. ${ }^{1} \mathrm{D} 031705$ y D031706: aquí se incluyen feldespatos en general, al menos un $10 \%$ de plagioclasa y una fracción de feldespato alcalino; ${ }^{2} \mathrm{D} 031708$ : muestra con matriz difícil de diferenciar, aunque ocupa al menos un $20 \%$ (se realizó el conteo de minerales sin distinguir entre fenocristales y matriz).

Lat.: latita; And.: andesita; vít.: vítreo(a); biot.: biotita; ves.: vesicular; "+”: "con”.

\section{Génesis}

Al igual que para la Unidad Kámuk, se sugiere que el emplazamiento de estas rocas fue somero, aunque no es claro si los productos actualmente observados son domos extrusivos o si se trata de criptodomos. En este trabajo se considera que la Unidad Dúrika consiste principalmente de criptodomos, tal y como se observa en la figura 9.

\section{Unidad Río Lori ( $\alpha 4)$}

Se utiliza la denominación Unidad Río Lori para referirse a las rocas extrusivas calcoalcalinas, predominantemente dacíticas, que se han reportado hacia la región central de la cordillera de Talamanca. Las estructuras asociadas con esta unidad (coordenadas L5, L6 y M6 del mapa adjunto) se interpretan como domos extrusivos, y han sido descritos por ONU (1975), Ballmann (1976), Tournon (1984) y Abratis (1998).

\section{Descripción}

Se trata de rocas dacíticas o andesíticas con un alto contenido de sílice (generalmente entre 60 y $70 \%$ del total de la roca), con fenocristales de plagioclasa, cuarzo corroído, anfíbol y biotita (ONU, 1975; Ballmann, 1976; Tournon, 1984; Abratis, 1998). La plagioclasa es andesina (ONU, 1975), y aparece tanto en fenocristales como en la matriz. También pueden presentarse xenocristales de olivino o xenolitos glomeroporfiríticos con clinopiroxeno, plagioclasa y olivino (Abratis, 1998). La matriz es criptocristalina, a veces desvitrificada con tridimita (Tournon, 1984). 


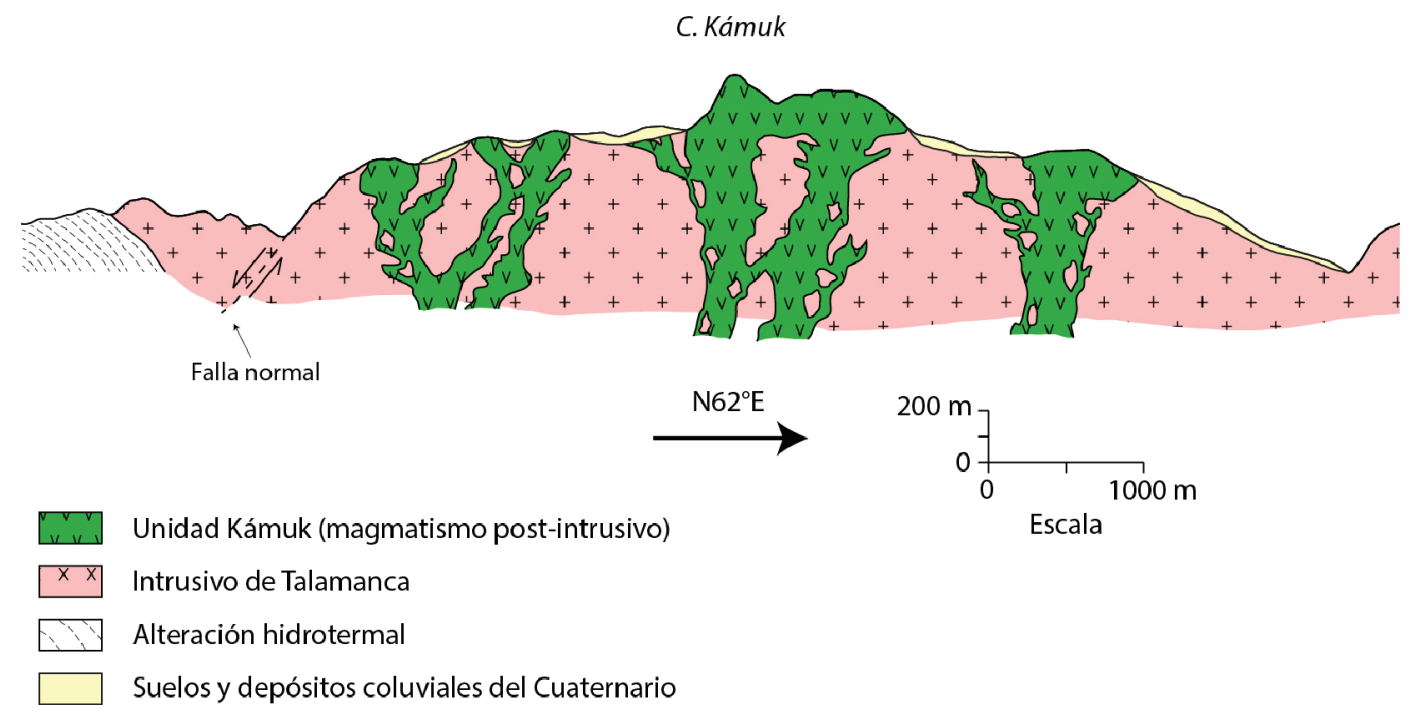

Fig. 8: Perfil geológico esquemático del cerro Kámuk.

Geomorfológicamente la Unidad Río Lori sobresale por tratarse de cerros bien diferenciados, de unos $400 \mathrm{~m}$ de elevación máxima sobre el terreno circundante.

\section{Estratotipo}

El estratotipo se sitúa hacia la región central de la cordillera de Talamanca, unos $25 \mathrm{~km}$ al NNE de Buenos Aires. Las mejores exposiciones se encuentran en los domos más meridionales. El domo en las coordenadas 546300 E, 369000 $\mathrm{N}$ (ver mapa adjunto y hoja topográfica Siola) es una prominencia de interés por su aspecto de estructura cónica truncada y sus pendientes escarpadas, según se observa desde los cerros Utyum.

\section{Distribución geográfica}

Esta unidad podría ser exclusiva de la región central de la Talamanca, aunque hay rocas andesíticas en las cercanías de San Vito que presentan edades similares.

\section{Edad y correlaciones}

Existen tres dataciones de las dacitas en los alrededores del río Lori. De Boer et al. (1995) reportan edades de 2,80 $\pm 0,05$ y $0,95 \pm 0,01$ millones de años (K/Ar). La única datación $\mathrm{Ar}^{40} / \mathrm{Ar}^{39}$ es la de Abratis y Wörner (2001), 1,90 \pm 0,17 millones de años (ver datación 1., coordenadas L6 en el mapa adjunto)

Las edades aquí mencionadas son correlacionables con la del Tajo La Lucha, cerca de San Vito (fuera del área de estudio), donde MacMillan et al. (2004) reportan una andesita de 1,490 $\pm 0,020$ millones de años $\left(\mathrm{Ar}^{40} / \mathrm{Ar}^{39}\right)$.

\section{Génesis}

La Unidad Río Lori corresponde con domos extrusivos que se conservan conspicuos debido a que su actividad es relativamente reciente (Fig. 9), o con relictos volcánicos profundamente erosionados (ONU, 1975). Tournon (1984, pág. 159) describe que los domos "se asientan sobre un mismo batolito granítico". 
Se considera que los domos de la Unidad Río Lori constituyen los únicos relictos estrictamente volcánicos en el sector central de la cordillera, y que las demás rocas volcánicas post-intrusivas, si las hubo, ya han sido removidas por la erosión. Esta ha sido diferencial: los criptodomos de las unidades Kámuk y Dúrika son más difíciles de erosionar que el Intrusivo de Talamanca, por lo que constituyen las cimas tras el levantamiento y la consecuente denudación (Fig. 9). Futuro trabajo de campo en los sectores más elevados de la cordillera determinará la validez de esta idea.

\section{CONCLUSIONES}

- Se reconocen 5 fases magmáticas en la cordillera de Talamanca, diferenciables petrográficamente y cartografiables: 1) Unidad Lohmann y Formación La Cruz, rocas ígneas extrusivas del Mioceno Inferior a Medio con una paragénesis de plagioclasa, clinopiroxeno y olivino; 2) Intrusivo de Talamanca, del Mioceno Medio a Superior (12 a 7,5 millones de años atrás) con plagioclasa, ortosa, cuarzo, hornblenda verde, clinopiroxeno y biotita como asociación más frecuente; 3 ) Unidad Kámuk, del Mioceno Superior cuspidal al Plioceno, con plagioclasa de tipo labradorita, clinopiroxeno y ortopiroxeno como fenocristales; 4) Unidad Dúrika, probablemente de la misma edad que la Unidad Kámuk, con plagioclasa de tipo andesina, feldespato potásico, biotita (ferromagnesiano predominante) y clinopiroxeno; y 5) Unidad Río Lori, con plagioclasa de tipo andesina, cuarzo, anfíbol como mineral ferromagnesiano predominante y biotita.

- Los intrusivos son difícilmente separables por criterios petrográficos, aunque se observa una tendencia general a encontrar rocas plutónicas más félsicas en las partes bajas (bajo los $1500 \mathrm{~m}$ s.n.m.) y más básicas en las partes altas (sobre los $2500 \mathrm{~m}$ s.n.m.). No es claro si los gabros en general son más antiguos que las monzonitas y granitos, o si hay gabros incluso más jóvenes que estos.

- Se interpreta que las unidades Kámuk y Dúrika que afloran en los sectores más elevados de la cordillera son en su mayoría cuerpos hipoabisales (criptodomos) y no productos de vulcanismo post-intrusivo; es decir, estos productos, si los hubo, ya están erosionados. Los únicos productos de vulcanismo efusivo o explosivo hacia las partes altas de la cordillera corresponden con la Unidad Río Lori, domos edificados sobre los plutones ya erosionados.

- El trabajo de campo permite definir la constitución de algunas de las principales cimas de la cordillera de Talamanca:

o Cerros Cuericí: la cima oeste está formada por rocas volcánicas o subvolcánicas hidrotermalizadas, la cima central por andesitas con ortopiroxeno y clinopiroxeno, y la cima este por brechas polimícticas, esencialmente volcanoclásticas.

o Cerro Chirripó: Leucogabro cuarzoso con megaxenolitos de basalto o andesita con alteración potásica.

o Cerro Ena: Brechas volcanoclásticas fosilísferas.

o Cerro Dúrika: Latita biotítica.

o Cerro Utyum: Latita biotítica.

o Cerro Kámuk: Andesita con clinopiroxeno.

o Cerro Echandi: Leucogabro cuarzoso.

- No se pudieron diferenciar petrográficamente las rocas ígneas pre-intrusivas, agrupadas aquí en dos unidades diferentes: Lohmann y La Cruz. La división se estableció con base en diferencias en los patrones de tierras raras livianas (Alfaro, 2017), y con una idea análoga a la situación estratigráfica al sur del Valle Central (Unidad Lohmann sería un equivalente temporal de la Formación Pacacua). Esto debe verificarse con un trabajo posterior.

- El contenido de anortita de las plagioclasas y la abundancia relativa de los minerales ferromagnesianos son los dos criterios más útiles para establecer una diferenciación entre las rocas ígneas post-intrusivas.

- Se recomienda, si es posible, visitar sitios de los que aún no hay información geológica disponible en la literatura, para tener al menos una idea de su constitución. Entre ellos se destacan cerro Fábrega en Panamá (considerado centro volcánico por Jackson, 1991), cerros Brunka, Mok, Hakú, Amí, Amó, Bine, Sabanas de Dúrika, 


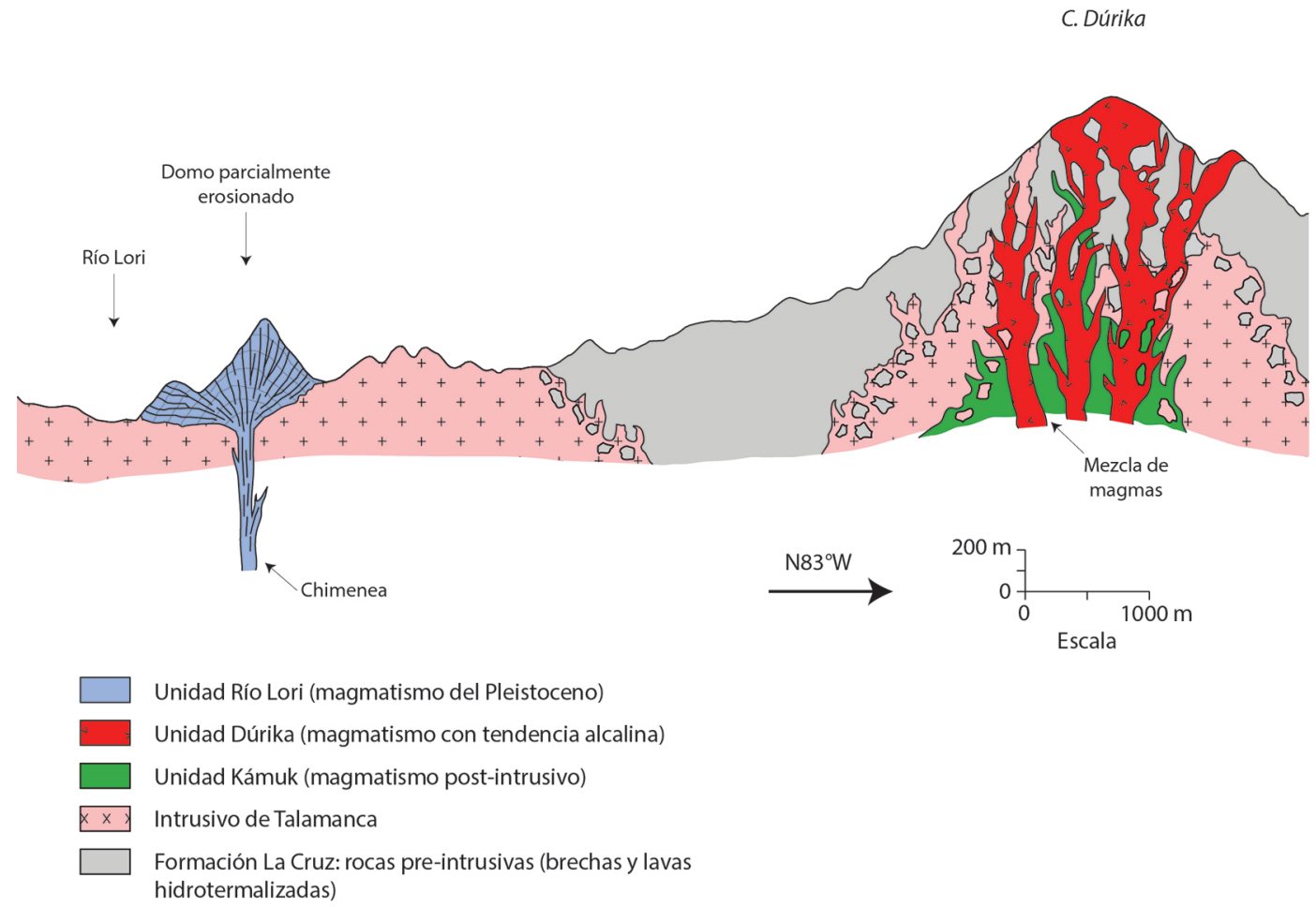

Fig. 9: Perfil geológico esquemático del cerro Dúrika, con la pendiente hacia el Caribe.

fila Norte (macizo de Chirripó), entre otros. En el Caribe de la Talamanca hay áreas de varios kilómetros cuadrados sin datos geológicos. Los trabajos de ONU (1975) y Cities Service Minerals (1977) siguen siendo los que cubren mayores extensiones en la pendiente al noreste de la divisoria de aguas.

- Los sectores del mapa con los códigos $\alpha-1$ y $\alpha$-t corresponden con lavas y tobas de edad desconocida, según el cartografiado de Cities Service Minerals (1977). La posición estratigráfica y las características de estas rocas no están bien definidas, por lo que se han separado de las unidades descritas en este trabajo. Ciertas áreas denominadas con $\alpha-1$ en el sector Pacífico (coordenadas D3 y D4) se han separado porque su composición es traquítica (Drummond et al., 1995), y no corresponden con ninguno de los grupos aquí presentados.

- Las Sabanas de Dúrika (ver hoja topográfica Dúrika) constituyen una meseta de más de 2300 m s.n.m., unos $14,4 \mathrm{~km}^{2}$ de superficie y delimitada hacia el norte por escarpes profundos que tienden a formar una pared curva y muy irregular, según se observa en los mapas topográficos. Se ha especulado desde hace varias décadas sobre su geología y posible origen (ONU, 1975; Tournon y Alvarado, 1997; Denyer y Alvarado, 2007; Alfaro, 2017). Las Sabanas de Dúrika aún permanecen inexploradas geológicamente.

- Las cimas de los cerros Kámuk, Dúrika y Chirripó presentan excelentes afloramientos que merecen estudiarse con un detalle mucho más profundo que el de este trabajo. La cima del Ena podría ser de interés desde el punto de vista paleontológico y sedimentológico (ver Alfaro, 2017), aunque es difícil encontrar buenas exposiciones. En las cimas de Cuericí, Utyum y Echandi no se observaron buenos afloramientos, al menos en las proximidades de los senderos (ver mapa adjunto). Futuras incursiones podrían encontrar nuevas evidencias sobre la evolución geológica de la región en esos macizos. 


\section{AGRADECIMIENTOS}

Se agradece a Ronald Chan, Gravin Villegas, Roger González y Marisol Rodríguez, del Área de Conservación La Amistad-Pacífico, por aprobar la realización del trabajo de campo dentro del Parque Internacional La Amistad y el Parque Nacional Chirripó. A los guías Omar Zúñiga, Freddy Quirós, Yendry Rojas, Freddy Acuña, Héctor Vargas, Luis Rojas y Olmer Mora, quienes hicieron posible el trabajo de campo. Un especial agradecimiento a Gerardo Soto por la revisión del manuscrito, sus comentarios y sugerencias, que definitivamente contribuyeron a su mejoramiento. A Oscar Lücke, Pablo Ruiz, Manuel Barrantes, Pilar Madrigal, Andrés Ulloa y Luis Obando por sus observaciones sobre petrografía u otros aspectos geológicos de la región. Este trabajo es una contribución al proyecto 830 B0-242, Fortalecimiento de la Investigación en Estratigrafía y Tectónica, de la Vicerrectoría de Vida Estudiantil de la Universidad de Costa Rica.

\section{REFERENCIAS BIBLIOGÁFICAS}

Abratis, M. (1998). Geochemical variations in magmatic rocks from southern Costa Rica as a consequence of Cocos Ridge subduction and uplift of the Cordillera de Talamanca (Tesis de doctorado inédita). Geochemisches Institut, Universidad de Göttingen, Alemania.

Abratis, M. y Wörner, G. (2001). Ridge collision, slab-window formation, and the flux of Pacific asthenosphere into the Caribbean realm. Geology, 29(2), 127-130.

Alfaro, A. (2017). Caracterización petrográfica y geoquímica de las rocas ígneas en el sector Pacífico de la cordillera de Talamanca, Costa Rica (Tesis de licenciatura inédita). Universidad de Costa Rica, San José, Costa Rica.
Alvarado, G. E., Barquero, R., Taylor, W., Mora, M., Peraldo, G., Salazar, G. y Aguilar, T. (2009a). Geología de la Hoja San Isidro, Costa Rica. Revista Geológica de América Central, 40, 111-122.

Alvarado, G. E., Barquero, R., Taylor, W., López, A., Cerdas, A. y Murillo, J. (2009b). Geología de la Hoja General, Costa Rica. Revista Geológica de América Central, 40, 98-107.

Alvarado, G. E. y Gans, P. B. (2012). Síntesis del magmatismo, metamorfismo y metalogenia en Costa Rica, América Central. Revista Geológica de América Central, 46, 6-122.

Alvarado, P., Aragón, E., Calero, G. A., Carballo, R., Chaves, P., Delgado, R., Flores, R., Fonseca, M. F., González, L. P., Guadamuz, D., Gutiérrez, A., Jiménez, M. F., Jiménez, J., Obando, A., Picado, C., Porras, J. L., Quirós, D., Solano, J. P., Valerio, A., Vargas, J. E., Vásquez, K. y Zúñiga, Y. (2015). Geología de una parte de las hojas Repunta y Coronado. San José, Costa Rica: Universidad de Costa Rica. Informe de Campaña Geológica inédito.

Appel, H. (1990). Geochemie und K/ArDatierung an magmatien in Costa Rica, Zentralamerika (Tesis de maestría inédita). University of Mainz, Germany.

Arroyo, I. (2001). Sismicidad y neotectónica en la región de influencia del proyecto Boruca: hacia una mejor definición sismogénica del Sureste de Costa Rica (tesis de licenciatura inédita). Universidad de Costa Rica, San José, Costa Rica.

Ballmann, P. (1976). Eine geologische Traverse des Ostteils der Cordillera de Talamanca, Costa Rica (Mittelamerika). Neues Jahrbuch fuer Geologie und Paleontologie, 8, 502-512. 
Barrantes, M. (1991). Comentarios petrográficos de algunas rocas aflorantes en la región central de Costa Rica. Revista Geológica de América Central, 12, 75-82.

Bellon, H. y Tournon, J. (1978). Contribution de la géochronométrie K-Ar a l'etudie du magmatisme de Costa Rica. Bulletin Société Géologique de France, xx, 6, 955-959.

Bergoeing, J. P. (1982). Dataciones radiométricas de algunas muestras de Costa Rica. Informe Semestral del Instituto Geográfico Nacional, 28, 71-86.

Berrangé, J. P. y Whittaker, J. E. (1977). Reconnaissance Geology of the Tapanti Quadrangle, Talamanca Cordillera, Costa Rica (Report 37). Londres: Institute of Geological Sciences, .

Boschini, I. M., Alvarado, G. E. y Rojas, W., (1988). El terremoto de Buenavista de Pérez Zeledón (julio 3, 1983): evidencia de una fuente sismogénica intraplaca desconocida en Costa Rica. Revista Geológica de América Central, 8, 111-121.

Calvo, G. (1987). Geología del macizo del Chirripó, cordillera de Talamanca, Costa Rica. San José, Costa Rica: Universidad de Costa Rica. Informe de Campaña Geológica inédito.

Cities Service Minerals (1977). Talamanca Cordillera, Province of Limon - Geological map (incluye las hojas Río Banano, Siola, Namaki, Sukut, Telire, Estrella, Kámuk, Dúrika, Matama y Chirripó) (Escala 1:50 000). San José, Costa Rica: Cities Service Minerals (Circum-Caribbean) S.A.

Compañía Petrolera de Costa Rica, Departamento de Exploración (1960). Compilación Geológica de la Provincia de Limón
(Escala 1:100000). San José, Costa Rica: Departamento de Geología, Dirección General de Exploración Minera, RECOPE.

De Boer, J. Z., Drummond, M. S., Bordelon, M. J., Defant, M. J., Bellon, H. y Maury, R. C. (1995). Cenozoic magmatic phases of the Costa Rica Island Arc (Cordillera de Talamanca). En P. Mann (ed.), Geologic and Tectonic Development of the Caribbean Plate Boundary in Southern Central America (Special Paper, 295, pp. 33-55). Boulder, Colorado: Geological Society of America.

Dengo, G. (1962). Tectonic-Igneous Sequence in Costa Rica. En A. E. J. Engel, H. L. James y B. F. Leonard (eds), Petrologic Studies: A Volume to Honor A. F. Budington (pp. 133161). Boulder, Colorado, Estados Unidos: Geological Society of America.

Dengo, G. y Escalante G. (1980). Mapa preliminar y de reconocimiento geológico y fotogeológico: zona de influencia de la cuenca del río Savegre (Escala 1:50000.). San José, Costa Rica.

Denyer, P. y Arias, O. (1991). Estratigrafía de la región central de Costa Rica. Revista Geológica de América Central, 12, 1-59.

Denyer, P. y Alvarado, G. E. (2007). Mapa geológico de Costa Rica (Escala 1:400000). San José, Costa Rica: Librería Francesa, S. A.

Denyer, P., Montero, W. y Alvarado, G. E. (2013). Atlas tectónico de Costa Rica. San José, Costa Rica: Editorial Universidad de Costa Rica.

Drummond, M. S., Bordelon, M., de Boer, J. Z., Defant M. J., Bellon, H. y Feigenson M. D. (1995). Igneous petrogenesis and tectonic setting of plutonic and volcanic rocks of 
the Cordillera de Talamanca, Costa RicaPanama, Central American Arc. American Journal of Science, 295, 875 - 919.

Escalante, G. (1978). Mapa geológico preliminar - Área sureste de Costa Rica (Cordillera de Talamanca y zonas adyacentes) (Escala 1:200 000). San José, Costa Rica: IGN.

Fischer, S. y Pessagno, E. A. (1965). Upper Cretaceous strata of northwestern Panama. Bulletin American Assosiation of Petroleum Geologists, 49 (4), 433-444.

Fisher, D. M., Gardner, T. W., Sak, P. B., Sánchez, J. D., Murphy, K. y Vannuchi, P. (2004). Active thrusting in the inner forearc of an erosive convergent margin, Pacific coast, Costa Rica. Tectonics, 23. doi: 10.1029/2002TC001464.

Gabb, W. M. (1874). On the Geology of the Republic of Costa Rica, 1874. [Transcripción de Lücke, O. H., Gutiérrez, V. y Soto, G. (2007). Del original del manuscrito de la biblioteca del U.S. Geological Survey, bajo la signatura 203(386)Gg20]. Revista Geológica de América Central, 37, 103-118.

Gazel, E., Alvarado, G. E., Obando, J. y Alfaro, A. (2005). Geología y evolución magmática del arco de Sarapiquí. Revista Geológica de América Central, 32, 13-31.

Gazel, E., Carr, M. J, Hoernle, K., Feigenson, M. D., Szymansky, D., Hauff F. y van den Bogaard, P. (2009). Galapagos-OIB signature in southern Central America: Mantle refertilization by arc-hot spot interaction. Geochemistry, Geophysics and Geosystems, doi: 10.1029/2008GC002246.
Gazel, E., Hoernle, K., Carr, M. J., Herzberg, C., Saginor, I., van den Boogard, P., Hauff, F., Feigenson, M. y Swisher III, C. (2011). Plume-subduction interaction in southern Central America: Mantle upwelling and slab melting. Lithos, 121, 171-134.

Gazel, E., Hayes, J., Hoernle, K., Kelemen, P., Everson, E., Holbrook, W. S., Hauff, F., van den Boogard, P., Vance, E. A., Chu, S., Calvert, A. J., Carr, M. y Yodgodzinski, G. M. (2015). Continental crust generated in oceanic arcs. Nature Geosciences. doi: 10.1038/NGEO2392.

Gräfe, K. (1998). Exhumation and thermal evolution of the Cordillera de Talamanca (Costa Rica): constraints from fission track analysis, ${ }^{40} \mathrm{Ar}-{ }^{39} \mathrm{Ar}$, and ${ }^{87} \mathrm{Rb}-{ }^{87} \mathrm{Sr}$ chrono$\log y$ (Tesis de doctorado inédita). Institut für Geologie und Paläontologie, Tubinga, Alemania.

Gräfe, K., Frisch, W., Villa, I. M. y Meschede, M. (2002). Geodynamic evolution of southern Costa Rica related tol w-angle subduction of the Cocos Ridge: constraints from thermochronology. Tectonophysics, 348, 187-204.

Hoernle, K., Abt, D. L., Fischer, K. M., Nichols, H., Hauff, F., Abbers G. A., van den Boogard, P., Heydolpf, K., Alvarado, G., Protti, M. y Strauch, W. (2008). Arc parallel flow in the mantle wedge beneath Costa Rica and Nicaragua. Nature, 451, 1094-1097.

Jackson, T. E. (1991). Neogene Geochemistry of the Central American Arc: western Panama and Southeastern Costa Rica (Tesis de maestría inédita). University of South Florida, Florida, Estados Unidos. 
Kolarsky, R., Mann, P. y Montero, W. (1995). Island arc response to shallow subduction of the Cocos Ridge, Costa Rica. En P. Mann (ed.), Geologic and Tectonic Development of the Caribbean Plate Boundary in Southern Central America (Special Paper, 295, pp. 235-262). Boulder, Colorado: Geological Society of America.

Kussmaul, S. (1987). Petrología de las rocas intrusivas neógenas de Costa Rica. Revista Geológica de América Central, 7, 83-111.

LaFemina, P., Dixon, T., Govers, R., Norabuena, E., Turner, H., Saballos, A., Mattioli, G., Protti, M. y Atrauch, M. (2009). Fore-arc motion and Cocos Ridge collision in Central America. Geochemistry, Geophysics and Geosystems. doi: 10.1029/2008GC002181.

MacMillan, I., Gans, P. y Alvarado, G. E. (2004). Middle Miocene to present plate tectonic history of the Central American Volcanic Arc. Tectonophysics, 392, 325-348.

Montero, W. (2001). Neotectónica de la región central de Costa Rica: frontera oeste de la microplaca de Panamá. Revista Geológica de América Central, 24, 29-56.

Mora, S. (1979). Estudio geológico de una parte de la región sureste del Valle del General, Provincia de Puntarenas, Costa Rica (Tesis de licenciatura inédita). Universidad de Costa Rica, San José, Costa Rica.

Morell, K. D. (2015). Late Miocene to recent plate tectonic history of the southern Central America convergent margin. Geochemistry, Geophysics and Geosystems. doi: 10.1002/2015GC005971.
Obando, L. G. (2004). Geología y petrografía del Cerro Buenavista (Cerro de la Muerte) y alrededores, Costa Rica. Revista Geológica de América Central, 30, 31-39.

Obando, L. G. y Kussmaul, S. (2009). Geología de la Hoja Buenos Aires, Costa Rica. Revista Geológica de América Central, 41, 123-136.

OEA (1977). Diagnóstico del sector minero. San José, Costa Rica: OEA.

ONU (1975). Proyecto de investigación minera, Talamanca, Costa Rica. Nueva York, Estados Unidos.

Rivier, F. (1985). Sección geológica del Pacífico al Atlántico a través de Costa Rica. Revista Geológica de América Central, 2, 23-32.

Romanes, J. (1912). Geology of a Part of Costa Rica. Quarterly Journal of the Geological Society, 68, 103-139. doi: 10.1144/GSL. JGS.1912.068.01-04.09.

Segura, A. (1978). Informe geológico de la exploración de los permisos mineros solicitados por SAMCOSA. San José, Costa Rica. Informe inédito.

Sella, G., Dixon, T. H., y Mao (2002). REVEL: A model for Recent plate velocities from space geodesy. Journal of Geophysical Research, doi: 10.1029/ 2000JB000033.

Sitchler, J. C., Fisher, D. M., Gardner, T. y Protti, M. (2007). Constraints on inner arc deformation from balanced cross sections, Fila 
Costeña Thrust Belt, Costa Rica. Tectonics, 26, doi: 10.1029/2006TC001949.

Schplein, R. (s.f.). Mapa geológico de parte de la hoja Cabagra (Escala 1:50000). Mapa inédito.

Sprechmann, P. (ed.). (1984). Manual de geología de Costa Rica. San José, Costa Rica: Editorial Universidad de Costa Rica.

Tournon, J. (1984). Magmatismes $d u$ Mesozoique a l'Actuel en Amerique Centrale: L'example de Costa Rica, des Ophiolites aux Andesites (Tesis de doctorado inédita). Universidad Curie, París, Francia.

Tournon, J. y Alvarado, G. E. (1997). Mapa geológico de Costa Rica, Folleto Explicativo. Cartago, Costa Rica: Editorial Tecnológica de Costa Rica.
Ulloa, A. y Delgado, C. (2010). Características geoquímicas y mineralogía del flanco Pacífico Central de la Cordillera de Talamanca: implicaciones para la evolución de una corteza continental (Tesis de licenciatura inédita). Universidad de Costa Rica, San José, Costa Rica.

Van Uffelen, J. G. (1993). A geological Geomorphological and soil transect study of the Chirripo massif and adjacent areas, Cordillera de Talamanca, Costa Rica. Turrialba, Costa Rica: CATIE.

Weyl, R. (1957). Contribución a la geología de la Cordillera de Talamanca de Costa Rica (Centro América). San José, Costa Rica: Instituto Geográfico Nacional.

Wunsch, O. (1987). Geologie gebiet Chirripó (Escala 1:12 500). Berlin: Institut für Geologie und Paläontologie der Freinen Universität. 